\title{
Meteorological Navigation by Integrating Metocean Forecast Data and Ship Performance Models into an ECDIS-like e-Navigation Prototype Interface
}

\author{
Andrea Orlandi ${ }^{1, *}$, Andrea Cappugi ${ }^{2}$, Riccardo Mari ${ }^{1,3}$, Francesco Pasi ${ }^{1,3}$ and Alberto Ortolani ${ }^{1,3}$ (D) \\ 1 Consorzio LaMMA, c/o CNR-IBE, Florence Research Area, Via Madonna del Piano n.10, Edificio D, \\ 50019 Sesto Fiorentino (FI), Italy; mari@lamma.toscana.it (R.M.); pasi@lamma.toscana.it (F.P.); \\ ortolani@lamma.toscana.it (A.O.) \\ 2 Tate s.r.l., Via Enrico Mattei n.106, 40138 Bologna, Italy; andrea@tate.it \\ 3 CNR-IBE, Florence Research Area, Via Madonna del Piano n.10, Edificio D, 50019 Sesto Fiorentino (FI), Italy \\ * Correspondence: orlandi@lamma.toscana.it; Tel.: +39-055-448-301
}

check for updates

Citation: Orlandi, A.; Cappugi, A.; Mari, R.; Pasi, F.; Ortolani, A.

Meteorological Navigation by Integrating Metocean Forecast Data and Ship Performance Models into an ECDIS-like e-Navigation Prototype Interface. J. Mar. Sci. Eng. 2021, 9, 502. https://doi.org/10.3390/ jmse 9050502

Academic Editor: Roberto Vettor

Received: 2 April 2021

Accepted: 30 April 2021

Published: 7 May 2021

Publisher's Note: MDPI stays neutral with regard to jurisdictional claims in published maps and institutional affiliations.

Copyright: (c) 2021 by the authors. Licensee MDPI, Basel, Switzerland. This article is an open access article distributed under the terms and conditions of the Creative Commons Attribution (CC BY) license (https:// creativecommons.org/licenses/by/ $4.0 /)$.

\begin{abstract}
In the complex processes of route planning, voyage monitoring, and post-voyage analysis, a key element is the capability of merging metocean forecast data with the available knowledge of ship responses in the encountered environmental conditions. In this context, a prototype system has been implemented capable of integrating metocean models forecasts with ship specific performance data and models. The work is based on the exploitation of an open source ECDIS-like system originally developed in the e-Navigation framework. The resulting prototype system allows the uploading and visualization of metocean data, the consequent computation of fuel consumption along each analyzed route, and the evaluation of the encountered meteo-marine conditions on each route way point. This allows us to "effectively and deeply dig inside" the various layers of available metocean forecast data regarding atmospheric and marine conditions and evaluating their effects on ship performance indicators. The system could also be used to trigger route optimization algorithms and subsequently evaluate the results. All these functionalities are tailored in order to facilitate the "what-if" analysis in the route selection process performed by deck officers. Many of the added functionalities can be utilized also in a shore-based fleet monitoring and management center. A description is given of the modeling and visualization approaches that have been implemented. Their potentialities are illustrated through the discussion of some examples in Mediterranean navigation.
\end{abstract}

Keywords: route planning; meteo-marine forecasts; ship performance computation; graphical user interface; ECDIS

\section{Introduction}

Ships and marine vessel systems are part of logistic chains [1,2] and move in a complex geophysical environment [3]; moreover, they are subject to national and international regulations pertaining to several different levels: navigational safety and navigational rules [4], trading regulations, energy efficiency issues, and environmental protection measures (e.g., for a wide spectrum perspective, see References [5-14]). In this interconnected framework, modern navigation is a complex task where the conduction of each single voyage of the single ship is integrated in such a hierarchy of different contexts [15-17]. The development of e-Navigation [18-20] resources is expected to give relevant contributions to improve and rationalize such a modern integrated navigation. The e-Navigation concept, developed under the auspices of the United Nations International Maritime Organization (IMO), is finalized to increase safety and security in commercial shipping through better organization of data on ships and on-shore, and better data exchange and communication between the two and among ships [21-24]. In this context metocean conditions and weather routing applications [25-28] play a relevant role, not only in relation with off-shore and oceanic 
navigation, but also for coastal navigation and Short Sea Shipping [29-32]. Relevant examples of integrated navigation systems already available at the commercial level can be found in References [33-35].

Moreover, a single ship or marine vessel can be considered as a system with many interacting levels [36-39], some of them pertain to control and management issues and some others are directly linked to physical system dynamics [40]. All these levels are mutually interacting and many of them interact also with external factors like logistic chain constraints and the metocean environment. Thanks to the growth of data collection, storage and processing capabilities, observed data pertaining to the above mentioned levels can be integrated in the construction of ship specific Digital Twins [41-43]. Different modeling detail level can be adopted, with different grade of integration with observed data, generating a hierarchy of white box, gray box, and black box models [40]. The appropriate System Identification Techniques are to be used for models calibration and parameter estimation on one side, and for models validation on the other side. The implementation of such an integrated system of models has many relevant potentialities, and, in the field of the operational activity of each ship, it can help to improve and rationalize the pre-voyage route planning, the voyage execution processes and the post-voyage analysis.

The present work has been developed aware of such a scenario. It is focused on the meteorological navigation process, that is, on the complex activity of route planning and voyage profile selection, keeping into account the interplay between ship responses and environmental metocean conditions. In addition, en-route voyage monitoring and post-voyage analysis can be considered as part of this navigation process. The key element is the capability of making a clever and effective synthesis of the available metocean data with the knowledge on how a ship specifically responds to the encountered environmental conditions. Accordingly, a prototype system has been implemented in order to merge data from numerical models for atmospheric and oceanographic forecasts, with ship specific data and ship performance models. The work is aimed at developing a first prototype version of a software system that allows such a synthesis to be made by exploiting an open source ECDIS-like system. Additional features have been added to the e-Navigation Prototype Display (EPD) system, initially developed by the Danish Maritime Authority [44]. The resulting prototype system has a wider set of functionalities that, starting from the uploading and visualization of metocean data, enable the computation of fuel consumption along any selected route, the detailed examination of the encountered meteo-marine conditions on any route way point and the comparison of the results obtained for different routes. As a result, it is possible to effectively and "deeply dig inside" the various layers of available metocean forecast data regarding atmospheric and marine conditions. Such a system could be used to trigger route optimization algorithms and subsequently evaluate the results of such optimizations. All these functionalities are tailored in order to facilitate the "meteorological navigation" task, i.e., the "what-if" analysis in the route selection process performed by ship masters and deck officers, by exploiting graphic interfaces and presentation modes of common ECDIS systems, that they are well trained to work on. In addition, many of the added functionalities can be utilized also in a shore-based fleet monitoring and management center.

Given the overall framework set out above, the present work has to be considered as the first step of a research and development activity in which the main goal is to build-up software resources for improving the route planning activity, by synergistically merging academic solving approaches with professional sea requirements.

- The key element, and first requirement for the work, is the definition of a framework for an effective integration of detailed metocean data and ship modeling approaches with a graphical user interface very close to the industry standard utilized by seafarers in their real life at sea.

- From the development point of view, the main requirement is that such an integration be realized through a modular structure allowing a short response time for 
the "on-line" use, and allowing also systematic tuning and validation of algorithms and datasets.

As a first step, in this paper, the general context of the work is described highlighting the needed innovation, then the methodology is provided through details for the relevant implemented algorithms, and the main functionalities of the implemented prototype system are described through the discussion of representative case studies for a deeper understanding of the developments and their evaluation.

Further steps, still work in progress, are mainly focused on validation, tuning, and improvement through: (i) integration of the system with in-service recorded data; (ii) "inthe-field" testing phases aimed to asses and improve the effectiveness in real life activity; and (iii) parallel process of improvement of the interface, as well as with new functionalities. Some of these are related to the extension to a wider set of ship performance parameters, the integration of more informative meteocean data, like wave spectra, with the newest developments in ship modeling, their possible use in relation to operational dynamic stability conditions, and the use of ensemble prediction data for the exploitation of the forecast reliability assessment in the operational context. Many of these are already at a quite advanced development level in the respective research communities, but their full operational exploitation is still to come for the maritime sector, for which the present work aims at being a step forward.

Consequently, the manuscript is organized as follows: Section 2 provides a high level description of the prototype navigation system; in Section 3, details are given about the used metocean data, the adopted approaches for data access and geographic visualization, and the implemented ship modeling schemes, with a synthesis of their scientific and technical background; in Section 4, some of the system functions are illustrated, by considering case study voyages in the Mediterranean Sea; in Section 5, concluding remarks are drawn on the implemented system.

\section{The Prototype Navigation Interface: An Overview}

Starting from the basic functions typically found in an ECDIS system, the route for a given voyage can be defined. In Figure 1a, a route from Toulon (France) to Ajaccio (Corse, France) is shown as an example. In the bottom left side of panel, the corresponding dialogue window is present. It displays the details of the route as a whole and of each route way point and permits to edit and change several of them. These are functions already present in the original EPD system. The route shown in panel (a) is the straight shortest one, typically adopted in fair or weakly perturbed weather conditions. Analogously, in the right (b) panel of Figure 1, a zoom on the area is shown, where a variated route is added, and along-route metocean data have been loaded along it, in accordance with the voyage timing. These data are shown by arrow symbols typically adopted in ECDIS terminals, i.e., arrows with barbs: for wind; bold arrows: for waves; curvy arrows: for current. Route variations like the one shown in Figure $1 \mathrm{~b}$ are commonly adopted in order to minimize the effects of heavy weather. The entity of the deviation must be a compromise between the attempt to avoid the worst metocean conditions and the need to limit the consequent route length and fuel consumption increments. This decision-making process [45] is "manually" performed by ship officers of the deck, as well as with the aid of electronic and software aids, as metocean data visualization and automatic route optimization tools. 


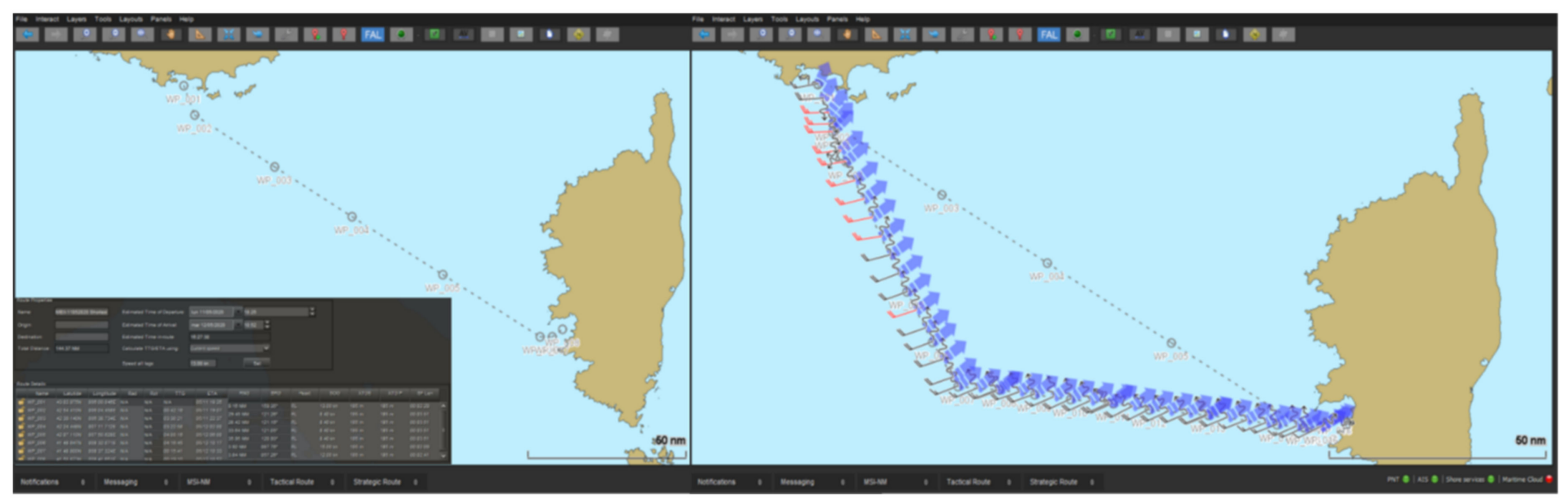

(a)

(b)

Figure 1. ECDIS-like routes visualization and editing in the prototype interface. Left panel (a): the shortest route from Toulon (France) to Ajaccio (Corse Island). Right panel (b): a little more zoom on the area and addition of a variated route with voyage timing-related metocean data shown with standard ECDIS-like graphics.

In the developed prototype system, improvements have been introduced through a higher level of integration of data and novel functions, in order to render more effective this process of route variation and evaluation.

A relevant improvement is obtained by the integrated loading of metocean forecast data maps, as shown in Figure 2. By selecting a given point on the route (by mouse clicking), metocean maps are loaded and data are shown for the time nearest to the one at which the ship reaches the selected point. It is possible to select the visualization of Wind Speed, or Current Speed, or Significant Wave Height (SWH) fields with the superposition of the respective direction arrows. As an example, in Figure 2, the SWH field is shown together with Wind Barbs, showing Wind Speed (with barbs standard coding) and Wind Direction (barbs on the tail and a little red dot on the head). Once the map has been loaded at the way point time, it is possible to load and show metocean data at the same time, but for different points (still by mouse clicking), as well as out from the route track. Moreover, it is possible to visualize polar diagrams of partitioned wave spectral data, if available in the loaded metocean data files. Such a polar diagram allows a synthetic but detailed characterization of the seaway-state at a given point and time. Each of the main wave components is described in terms of its intensity, through the partial SWH value represented by the corresponding symbol dimension and color, and in terms of Wave Peak Period and Peak Direction (of provenience), by the radial and directional position, respectively. Such data can also be directly visualized by hovering the mouse cursor upon each partition symbol. Through inspection of the diagram, it is possible to quickly understand if a wind sea component is present and if it is superimposed with one or more swell components, identifying the cases when complex multimodal crossed sea-states are forecast. 


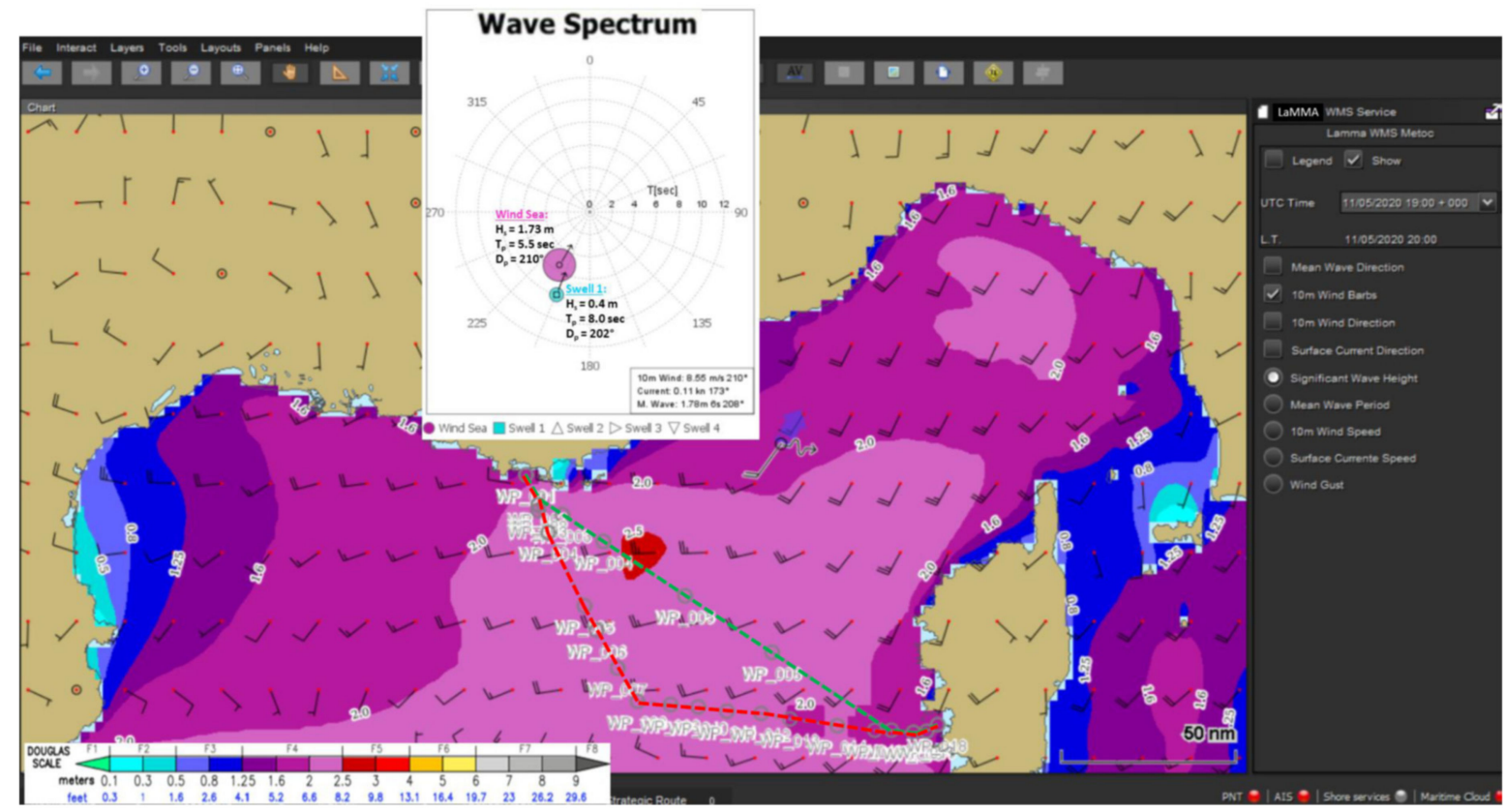

Figure 2. Loading of along-route-position time-correlated map of metocean forecast data. The SWH field is shown together with the surface Wind Barbs. Metocean data vectors are also shown in correspondence of a selected point, out of the route (same forecast time). In the "Wave Spectrum" window, the wave partitions diagram is shown (same point, same time).

An example is shown in the Wave Spectrum insert box of Figure 2, where the wave spectral components are shown for the point selected on the map and evidenced by metocean data arrows. A main wind sea partition of about $5 \mathrm{~s}$, from $\mathrm{SW}$, is present together with a slightly more southerly minority swell component of $8 \mathrm{~s}$ (see below in Section 3.1 and Figure 3 for a deeper description).

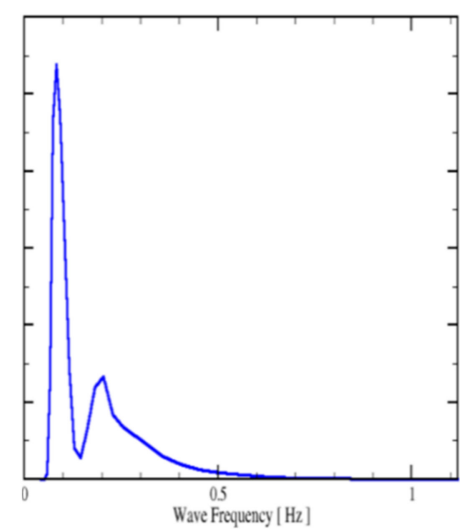

(a)

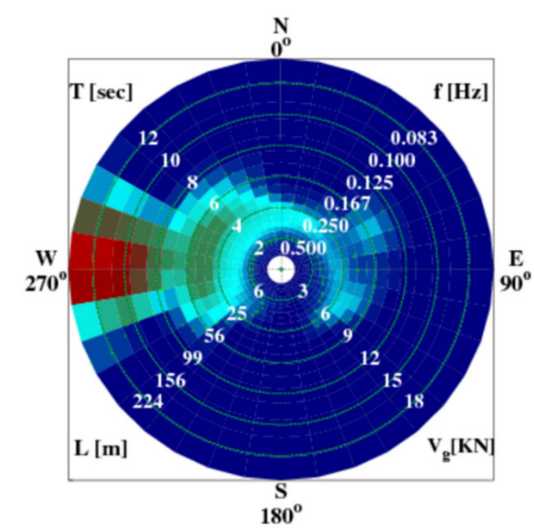

(b)

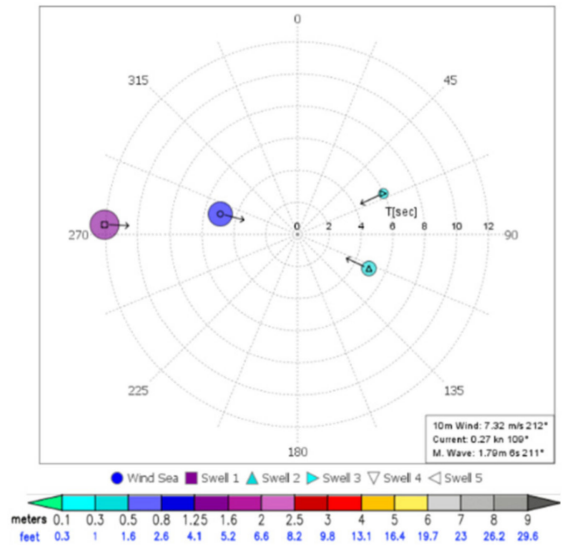

(c)

Figure 3. Different views of the same wave spectrum computed by WW3 model in proximity of the Capo Gallo RON buoy, for 03/10/2020 at 18:00 UTC. (a) One dimensional frequency spectrum. (b) Directional wave spectrum. (c) Corresponding wave partitions polar diagram.

The integrated inspection of along-route metocean data and time corresponding metocean maps allows us to evaluate how effective a route variation is in order to avoid adverse environmental conditions. The analysis can be completed by activating the computation of the fuel consumption along all the selected routes. The computation is performed by using ship specific data and ship performance computation algorithms as described in Section 3.2. 
The output is shown in a detailed table for each analyzed route (each route dataset is exportable in csv files, for further analysis) and in a "Routes sorting" panel, where all analyzed routes can be included and where the Total Fuel Consumption, Total Route Length and Total Voyage Time Duration are displayed. The possibility to sort the routes in the panel according to any one of these three quantities allows us to quickly detect the least consuming route, and to evaluate it through comparison with the others, as well as with respect to voyage duration, and also keeping in due account the voyage length. Furthermore, a detailed analysis of each route is possible thanks to the table display of the various parameters estimated along each route leg. This allows us to trace back the estimated fuel consumption rates to the effects of metocean conditions on the different ship resistance components in each part of the voyage. The capability to modify the route path and to select different ship powering configurations and speed values, for each leg in the route, permits to construct modified routes and then test the variations effects on partial and total voyage parameters, by enabling the computations on the modified routes and then including them into the "Routes sorting" panel.

If a (external) route optimization software [25-29] is available and delivers its outputs in standard route exchange format, its optimal solutions can be loaded into the prototype system and compared with other solutions resulting from the "handmade process". This can be done through the routes sorting panel, after activating the in-built fuel consumption computation. In this way, all routes are compared and evaluated by using the same ship data and performance simulation algorithms. It must be kept in mind that these algorithms are potentially different from those utilized to compute the cost function in the (external) route optimization software. A deeper level of integration will be reached by integrating route optimization algorithms directly inside the prototype system, and using this latter to trigger the optimal route computation process. This will guarantee algorithmic homogeneity by the use of the same ship data and modeling algorithms both for the fuel consumption optimization cost function and for the computations reported in the "Routes sorting" panel. Some preliminary tests with a route optimization algorithm have been already performed in Reference [46], with a simplified version of the ship modeling approaches described below.

A further level of the analysis comes out from the possibility to repeat the route computations by using metocean data from different runs of the forecast models chain and to include the results as different route solutions in the sorting panel. As an example, it is possible to repeat the computation of the same identical route configuration, by using metocean data from consecutive forecasts of the same set of models, or by comparing computations done by loading metocean data from different forecast centers. The stability and reliability of the forecasts, i.e., their uncertainties, can, thus, be estimated by directly analyzing the consequent effects on route and ship performance parameters spreading, helping to keep into account this relevant element when evaluating the possible introduction of a meteo-dependent route variation.

Considering the topic of metocean forecast data reliability, it must be pointed out that Ensemble Predictions Systems (EPS) [47] offer a rigorous way to quantitatively estimate uncertainties, and a correct processing of their outputs allows rigorous probabilistic forecasts to be formulated. The possible applications of the EPS approach are very promising also for meteorological navigation [48-51], and an EPS data visualization and exploitation tool will be soon implemented into the prototype interface.

\section{Data and Models}

Some details are given about the used metocean data, their loading and visualization, and about the implemented ship modeling schemes. Regarding this latter topic, not only the adopted approaches are described, but also alternative and potentially more detailed ones are briefly (and not exhaustively) reviewed in order to put in evidence a possible scenario for further development and improvement of the ship performance modeling components of the prototype system. 


\subsection{Metocean Data}

Metocean forecast data needed for the main functions of the prototype system are atmospheric surface wind and marine surface currents and waves. These are typically produced at forecasting centers by software chains composed of meteorological forecast models $[46,52,53]$, in which wind data are used to drive, in a one-way cascade mode, marine waves forecasting models [54-56]. Moreover, forecast for wind and other atmospheric variables, characterizing atmosphere-sea fluxes, are used to force marine hydrodynamics models $[57,58]$. As an improvement to these one-way cascade mode linked models' chains, two-way dynamically coupled atmosphere-waves-ocean modeling systems have been developed [59-61], and their application in operational forecasting contexts is promisingly growing.

Such metocean data are synergistically integrated in the prototype system for visualization and for ship performance evaluations. There are also other variables in output from atmospheric and marine hydrodynamics models, e.g., rainfall, fog, and visibility or sea level and water temperature. These are still not used in the prototype system, but their inclusion is straightforward and will be considered in future developments, in relation to their potential to further improve the route decision-making process.

The prototype system requires that the input metocean data be in the standard formats netcdf [62] or grib [63], that are commonly adopted by most of the forecasting centers. As a consequence, the system could be used for meteorological navigation worldwide.

The Mediterranean navigation examples described in this work are made by using data from an experimental configuration of the operational meteo-marine forecasting system of Consorzio LaMMA [64]. The meteorological component is based on the Weather Research and Forecasting (WRF) mesoscale [53] meteorological model, version 4.1 [65,66], with initialization and boundary conditions from the American global model (NOAA NCEP GFS) [67]. Wave forecasts data are generated by running, in cascade mode with respect to WRF, the third generation spectral wave model [54] Wavewatch III (WW3) version 6.07 [68]. The resulting wind-wave forecasting operational chain is run four times a day (initialization at 00, 06, 12, 18 UTC) over the whole Mediterranean Sea for the next seven days at a resolution of about $5 \mathrm{Km}$. Data for marine currents are from Copernicus Marine Service [69], namely from MEDSEA_ANALYSIS_FORECAST_PHY_006_013 (from the Mediterranean Sea Physics Analysis and Forecast system). It is based on the NEMO ocean model [70], in which v3.6 operational configuration covers the whole Mediterranean Sea, with a daily forecast repetition, at a resolution of about $4 \mathrm{Km}$.

As anticipated in Section 1, in the examples illustrated in Figures 1 and 2, metocean data can be visualized in terms of vectors for Wind and marine Current, Average Direction and SWH for waves, for any point along any route ("along route metoc") in accordance with voyage timing (Figure $1 \mathrm{~b}$, variated route). In this mode, metocean data can be directly ingested by accessing local files in standard grib or netcdf format, or by connecting to an OPeNDap server [71]. Moreover, maps of wind, current or waves fields can be visualized in the whole area of interest ("metoc maps"), as shown in Figure 2. The validity time of the data displayed on the map is selected, in accordance with voyage timing, by mouse clicking on points along the route. After this selection, it is also possible to visualize metocean data vectors, at the selected time, but on points out of the route (as shown in Figure 2) by mouse-clicking on the map. The "metoc maps" visualization mode exploits GIS standards [72] supported in the prototype system to access metocean data through a Web Map Service (WMS, [72]). For standard route analysis, the two visualization modes ("along route metoc" and "metoc maps") can be synchronized in order to show the same metocean data, but, alternatively, they can be targeted to different datasets, e.g., allowing the comparison between two forecast datasets.

A further visualization tool, that allows us to analyze wave data at a deeper level, is the spectral partitions polar diagram, as anticipated in Section 1 and shown in Figures 2 and 3.

Wave Partitioned data provide an effective synthesis of the wave spectral structure [73-75] in correspondence of the selected point in the map, at the selected time. In the polar diagram, 
each wave component present in the wave spectrum is shown with a specific "little" geometric symbol (inside a lager colored circular symbol): the circle for wind wave component, the square for the first (i.e., the main) swell component, the differently oriented triangles for the ordered sequence of the other (if present) four swell components (as shown in the bottom of the insert box). The position of the "little" symbols in the polar diagram allows us to graphically read the peak period (radial coordinate) and the peak direction of provenience (angular coordinate) of each respective partition. The colored circle of variable dimension surrounding each "little" symbol allows us to graphically read the partial SWH of each wave component in terms of its dimension and of its color filling (with the same palette of the total SWH shown in the map, e.g., Figure 2). The total SWH value, in which field can be visualized in the map, is given by the partitioned $\mathrm{SWH}$ values (in the polar diagram) added in quadrature [76]. An example is shown in Figure 3, where a sea state characterized by a multimodal wave spectrum is analyzed. The central panel (b) shows the polar diagram for the complete numerical directional wave spectrum, as computed by the WW3 model in correspondence of the position of the RON buoy offshore Capo Gallo, near Palermo, Sicily, Italy, for 03/10/2020 at 18:00 UTC. The value of the total SWH corresponding to that spectrum is about $1.8 \mathrm{~m}$. The directional spectrum shows that the total wave energy is mainly due to the presence of a very long and very tuned and collimated (directionally sharp spectral peak) swell component coming from the west, with a peak period of about $12 \mathrm{~s}$. This wave component had been generated several hours before by a relevant storm, with a very long fetch spanning from the Alboran Sea up to the Balearic Islands, westerly far away from Capo Gallo. Another wave component is present, with a peak period of about $5 \mathrm{~s}$, nearly collinear with respect to the dominant swell, and due to the local wind of about 16 knots, coming from WNW. Being the wind sea component it is characterized by a wide directional spreading. Two other very weak swell components are present, coming from the NE and SE quadrants, with peak periods in the range 5- $6 \mathrm{~s}$. The one-dimensional spectrum, obtained by integrating in the directional dimension, is shown on the left panel (a) of Figure 3. It allows us to well resolve the frequency position and highlight the energetic relevance of the long swell component peak with respect to the other components, the wind sea and the two minority swells. However, in this case, it does not allow to separate the peaks of these three components, because they are characterized by similar peak period (i.e., frequency) values and due to frequency spreading. Only a frequency)-directional diagram allows a clear separation of them. The polar diagram in the right panel (c) shows the spectral partitioning synthesis of the same multimodal wave spectrum. The partitioned SWH values from the WW3 partitioning algorithm $[68,75]$ are in this case: $0.9 \mathrm{~m}$ for the wind sea component ("little" circle symbol, from WNW); $1.5 \mathrm{~m}$ for the main swell ("little" square symbol, about from W); $0.4 \mathrm{~m}$ and $0.2 \mathrm{~m}$ for the two minority swells ("little" triangle up and left, from ESE and ENE, respectively). The color coding of the SWH values in the respective variable-dimension circles is shown in the palette bar reported at the bottom of the (c) panel. In the prototype interface, such data values can be directly visualized by a tooltip triggered by hovering the mouse cursor upon each partition symbol.

Through further development, this graphical representation could be integrated with the IMO guidelines for avoiding dangerous situations in adverse weather and sea conditions [77-80], and (when available) with X-band radar and other systems for on-board wave spectra measurement [81-85] in order to implement operational aids for ship safety. Due the potentially relevant impact of this matter, careful attention must be paid in implementing the related operational functionalities, as well as making reference to the evolving IMO Second Generation Intact Stability Regulations [86,87].

\subsection{Ship Modeling}

A relevant piece of information in the ship routing decision-making process is the total fuel consumption implied by a given route. It obviously depends on ship characteristics, and, once the route shape has been defined, it is determined by the speed profile and propulsion settings along the route, in strict relationship with the encountered meteo-marine conditions. The inherent complex bundle of kinematical and dynamical 
interrelationships can be approximated by a computational process, in order to obtain estimates of the fuel consumption, once the implied parameters have been fixed. The implemented ship modeling components in the prototype system can be exploited to guide deck officers to reliably perform such computations with the minimal effort. The inner computing core of this functionality has been implemented by decoupling the heaviest powering and aero-hydrodynamic computational tasks from the along-route meteo-dependent fuel consumption rate evaluations. This requires some approximations to be made, but the resulting computational framework remains sound, and allows improvements to be easily made if and where needed. Ship specific data are pre-computed and stored in Look-Up Tables (LUTs), to be quickly accessed and combined with metocean data through simple algebra. This allows us to obtain (through a numerical time integration) fuel consumption estimates with a fast and quickly repeatable procedure, as required by an effective meteorological navigation GUI.

The propulsive engine load and consequent fuel consumption rate are evaluated through the dynamic balance between propeller(s) thrust and ship's total resistance by applying standard algorithms [88-90]. In this process, the total resistance of the ship is evaluated by considering it as composed of two relevant terms:

$$
R_{\text {tot }}=R_{\text {hull }}+\Delta R,
$$

where $R_{\text {hull }}$ is the calm-water resistance [91-93] and depends on ship hull form, hull appendages, loading and trim conditions [94-96], and Speed Trough Water (STW). The growth of $R_{\text {hull }}$ with respect to STW is generally strong and it is one of the main elements that determine the ship's fuel consumption performance $[11,97,98]$. Hence, the dependence of $R_{\text {hull }}$ on STW, in the main loading conditions of the studied ship, is a relevant piece of information. Sometimes it is known from the design and construction process, after towing tank measurements [91,92,99], or through real ship sea trials [100-102]. It is also possible to compute it by applying simplified standard general purpose computational approaches [103-106], or by adopting tailored more complex and computationally intensive CFD approaches [107]. The added resistance term $\Delta R$ is considered as being composed of all the other relevant terms that need to be added to $R_{\text {hull }}$ in order to reliably estimate $R_{\text {tot }}$. As will be described below, the main terms of $\Delta R$ are strongly dependent on meteo-marine conditions. Once the dependence of $R_{\text {hull }}$ on STW is known in the speed range of interest, the propulsion powering problem can be solved pre-computing the fuel consumption rate $F R$ for several values of $S T W$ in such a range, and for several values of $\Delta R$, in a suitable range. For the completion of such computations, propeller-hull characteristics and engine data are needed. Propeller-hull characteristics are sometimes known from the design, construction and testing process. In alternative, it can be estimated by standard series approaches [108,109], or again by tailored heavy CFD [110,111]. Engine data can be extracted from user guides and data sheets delivered by the manufacturer. In order to span all the main alternatives, the computations should be repeated for the different propulsive settings adopted in the conduction of the given ship (e.g., number of active main engines, eventually active shaft generators, combinator settings in the case of CPP). Fouling growth on hull and propeller $[112,113]$ could be accounted for by repeating the computations with growing hull resistance curves (e.g., as a function of the time from the last hull cleaning), or by explicitly modeling this latter with different surface roughness levels. The dependence of the computed Fuel Rate LUTs on the main discretized variables can be indicated as follows:

$$
F R(i, j)=F R\left(S T W_{i}, \Delta R_{j}\right),
$$

where the $(i, j)$ dependence corresponds to the ship speed and added resistance discretized values (with suitable discretization steps). In addition (but not explicitly shown in Equation (2)) the dataset structure is also dependent on "ship-voyage configuration parameters" defining the different ship loading conditions and propulsive configurations. 
Once these latter have been selected, and the precomputed LUTs allow to simply pick up the estimated fuel consumption rate value $F R$ for each desired $S T W$, after the corresponding value of $\Delta R$ is estimated according to the encountered meteo-marine conditions.

In the approximation adopted in this work, the added resistance term is written as follows:

$$
\Delta R=R_{w i}+R_{a w},
$$

where $R_{w i}$ is the wind added resistance [91], due to the interaction of ship superstructures with the surrounding air, while $R_{a w}$ is the added resistance in waves [114], due to the hydrodynamic interaction of the ship with the field of the encountered marine surface waves.

The wind added resistance term depends on the total ship-relative wind, resulting from the vector composition of the ship Speed Over Ground (SOG) with the wind due to meteorological conditions. In idealized, completely calm environmental conditions, no wind nor sea waves of "meteorological origin" are present and the total resistance is well approximated by the sum of $R_{\text {hull }}$ and the $R_{w i}$ term due to the SOG only. It is evaluated by the expression $[91,115,116]$ :

$$
R_{w i}=0.5 \rho_{a i r} A_{T} U_{r}{ }^{2} C_{x}\left(\theta_{r w i}\right),
$$

where $\rho_{\text {air }}$ is air density, $A_{T}$ is the ship frontal area, and $U_{r}$ is the modulus of the ship-relative total wind vector. The longitudinal wind resistance coefficient $C_{x}=C_{x}\left(\theta_{\text {rwi }}\right)$ depends on ship above waterline structures and is function of the ship-relative wind angle $\theta_{r w i}$. It can be computed with a suitable discretization step, in the $0^{\circ}-360^{\circ}$ (or $0^{\circ}-180^{\circ}$, for symmetrical configurations) interval and stored as wind added resistance LUT. Differing functional shapes $C_{x}\left(\theta_{r w i}\right)$ can be stored in the wind resistance LUTs, depending on the ship configuration or loading condition (e.g., accounting for different loading conditions, or for different containers arrangement and filling factor [117]). The specific details of Rwi could be accounted for by ship specific $C x$ coefficients, from wind tunnel or/and from CFD [117-119]. In addition, other windrelated added resistance terms could be included through transverse forces and moments coefficients (Cy and CN, respectively) and corresponding "passive rudder" terms [120-122]. The inclusion of these latter terms could be useful for the meteorological navigation of ships with wind assisted propulsion [121-124], which is a strongly re-emerging field in connection with energy efficiency and pollution abatement issues [125-131].

The added resistance in waves term $R_{a w}$ in general confused seaways can be evaluated in terms of the spectral significant value integral [114]:

$$
R_{a w}=2 \int_{0}^{\infty} \int_{0}^{2 \pi} A R O\left(\omega, \theta_{\text {raw }}\right) S_{\zeta}\left(\omega, \theta_{\text {raw }}\right) d \theta_{\text {raw }} d \omega,
$$

where $A R O\left(\omega, \theta_{\text {raw }}\right)$ is the Added Resistance Operator, i.e., the longitudinal component of the drift force in regular waves per (regular) wave amplitude squared [114,132], while $S_{\zeta}\left(\omega, \theta_{\text {raw }}\right)$ is the directional wave spectrum, and the integration variables $\left(\omega, \theta_{\text {raw }}\right)$ are the wave "angular" frequency and the ship-relative (i.e., w.r.t. ship bow) wave direction. Computational approaches based on the full directional spectrum like those developed in References [51,133-135] have the potential of a high accuracy, but are computationally intensive and imply huge memory occupation for storing full spectra for the whole marine area and forecast time horizon. A less accurate, but strongly lighter approach, which allows us to pre-compute LUTs for $R_{a w}$, has been experimented in the present study. As a first step, the following wave spectrum factorization is introduced:

$$
S_{\zeta}\left(\omega, \theta_{\text {raw }}\right)=H_{s}{ }^{2} \Sigma_{\zeta}\left(\omega, \theta_{\text {raw }}\right),
$$

where $H_{s}$ is the $S W H$, in which square value is linked to the energy content of the sea state described by the spectrum, and $\Sigma_{\zeta}\left(\omega, \theta_{\text {raw }}\right)$ is the "unitary directional wave spectrum" [136], 
i.e., a spectrum with the same frequency-directional shape of $S_{\zeta}\left(\omega, \theta_{\text {raw }}\right)$, but with unitary SWH. As a result, $R_{a w}$ can be re-written as:

$$
R_{a w}=H_{s}^{2} C_{a w},
$$

where:

$$
C_{a}=2 \int_{0}^{\infty} \int_{0}^{2 \pi} A R O\left(\omega, \theta_{\text {raw }}\right) \Sigma_{\zeta}\left(\omega, \theta_{\text {raw }}\right) d \theta_{\text {raw }} d \omega .
$$

If a family of parametric spectra is introduced for approximating the shape of the "unitary" spectrum in Equation (8), a dataset of $C_{a w}$ values can be computed by allowing the relevant parameters to vary in suitable intervals, with suitable discretization steps. As an example, once fixed the spectral shape, its mean wave direction (w.r.t. ship bow) and period can be appropriately variated in order to obtain a sufficiently detailed representation of all the possible encounter conditions. The Added Resistance Operator functions $A R O\left(\omega, \theta_{\text {raw }}\right)$ needed for evaluating the numerical integral have to be computed by appropriate seakeeping hydrodynamic approaches [114,137-140]. A reasonably good approximation that can be adopted here is the Strip Theory [114,141], in one of its formulations, in which the general framework is compliant with the linear wave superposition approximation implied by the adoption of a spectral approach $[142,143]$. More accurate approaches, capable of accounting for the nonlinearities of added resistance in waves, could be utilized as in References [144-147], but paying a higher computational cost. On the other extreme, much simpler approaches could be inspired by the adoption of the JIP STAWAVE-1,2 approaches [148-150], originally developed for the processing of data from sea trials [101,102]. The ARO functions are obviously strongly ship dependent and for each ship, they must be computed for the relevant loading conditions and for various values of the ship speed STW in the speed range of interest, as for $R_{\text {hull }}$. The ship specific dataset to be precomputed and archived in the $C_{a w}$ LUTs have a functional dependence on the main discretized variables as follows:

$$
C_{a w}=C_{a w}\left(S T W_{i}, T_{m k}, D_{r m h}\right),
$$

where the integers $(i, k, h)$ are the discretization indices for STW, mean wave period $T_{m}$, and mean wave direction $D_{r m}$ (the subscript $r$ stands for ship-relative), respectively. After the $C_{a w}$ coefficients precomputing task have been completed for a given ship, its added resistance in waves can be estimated by the application of Equation (7), picking the right values of $H_{s}$ and of the $C_{a w}$ coefficient. This can be done by considering that it is sailing at a given $S T W$ in a seaway characterized by the values of $H_{s}, T_{m}$ and $D_{m}$. The mean wave direction in metocean data is usually relative to the North, and its value must be transformed into the ship-relative one, while the complex transformation to the encounter period [151] is usually already accounted for in the precomputed ship hydrodynamics for $A R O$.

In the present study, the PDSTRIP program [152] has been used for computing the $A R O$ functions (a modified version of the Boese approach $[153,154]$ is implemented in it). Example results computed for the S175 containership [155] are shown in Figure 4 (also see Table 1). In left and central panels, polar diagrams of the ARO, computed for a STW of 16.3 and 25 knots, are shown. These have been computed on a grid of wave directions (waves "from") in the $0^{\circ}-360^{\circ}$ interval, with steps of $10^{\circ}$, in the azimuthal direction, and wave period values in the radial direction. The wave period values cover the interval from 3 to $18 \mathrm{~s}$ (radial coordinates, green circles every $2 \mathrm{~s}$ ) also if, in the Mediterranean Sea wave climate, peak periods greater than $12 \mathrm{~s}$ are rare and spectral tails are always negligible over $13 \mathrm{sec}$. In the right panel, the head sea directional section of the S175 ARO is shown, as a function of $L_{p p} / \lambda$, in adimensional form to facilitate the comparison with other results. It has been computed for several Froude numbers, in good accordance with other literature results (e.g., see Reference [156]). 


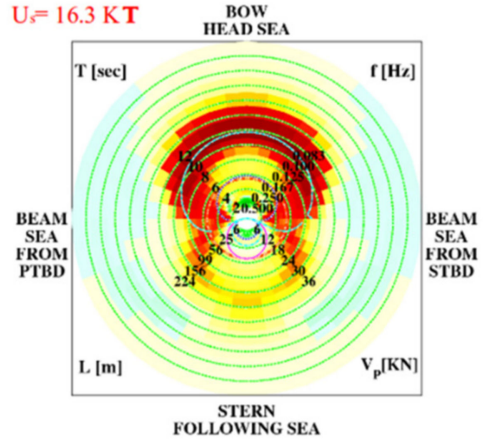

(a)

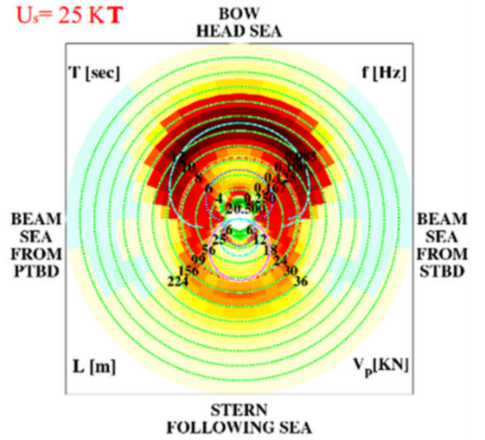

(b)

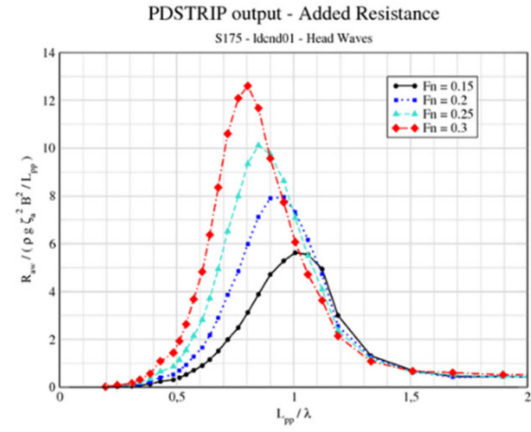

(c)

Figure 4. Added Resistance in waves Operator (ARO) computed by PDSTRIP for the S175 containership. (a) Polar plot of the $A R O$ at the speed of 16.3 knots. Red shading colors for the highest values, yellow shading for intermediate values, light cyan for small values. (b) Polar plot of the ARO at the speed of 25 knots. (c) Adimensional ARO for the head sea condition, computed by PDSTRIP for several values of the Froude number.

Table 1. Main particulars of the ships considered in the examples described in this article.

\begin{tabular}{ccc}
\hline Ship Main Particulars & RoPax & S175 \\
\hline Full load displacement $\Delta[\mathrm{t}]^{1}$ & 15,470 & 24,609 \\
Length between the perp.s L $\mathrm{pp}_{\mathrm{pp}}[\mathrm{m}]$ & 160 & 175 \\
Beam B [m] & 25 & 25 \\
Mean draft T [m] & 6.7 & 9.5 \\
\hline
\end{tabular}

${ }^{1}$ In the ship configuration settings of the prototype interface, this loading condition is labeled as ldcnd01.

For the generation of the $C_{a w}$ LUTs datasets, the JONSWAP parametric spectrum, with a $\cos ^{n}$ directional spreading function has been adopted, and the recommendations of [157] have been elaborated for the selection of the relevant parameters for the "generic" spectrum (to be distinguished from more "specific" wind sea and swell). In Figure 5, example $C_{a w}$ LUTs for the RoPax ship (see Table 1) considered in the case study of Section 4.1 are shown. They have been computed, with STW of 20 and 28 knots, with the "generic" parametric unitary wave spectrum as described above. The dependence on the relative direction of wave provenience $\left(D_{r m}\right)$ is shown in the half interval $0^{\circ}-180^{\circ}$ thanks to the port-starboard symmetry of the ship. The dependence on the average wave period $T_{m}$ is represented through multiple lines from 4 to $12 \mathrm{~s}$. In passing from 20 to 28 knots, the value of $C_{a w}$ exhibits a not negligible increase, as expected. For growing values of STW, the head sea resistance peak for high $T_{m}$ values ( $T_{m}$ around $10 \mathrm{~s}$, i.e., peak period $T_{p}$ slightly lower than $12 \mathrm{~s}$ ) becomes more and more prominent, while, for lower values of $T_{m}$, a resistance peak is present for "bow-quartering" waves. 


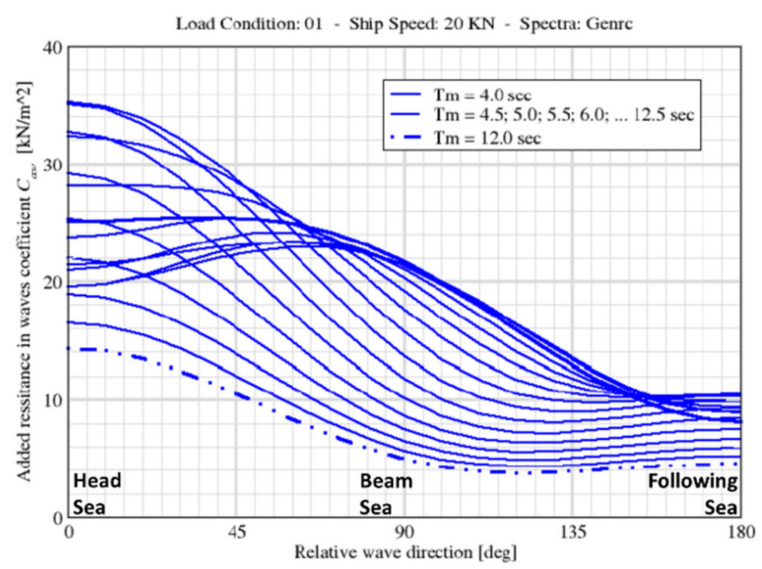

(a)

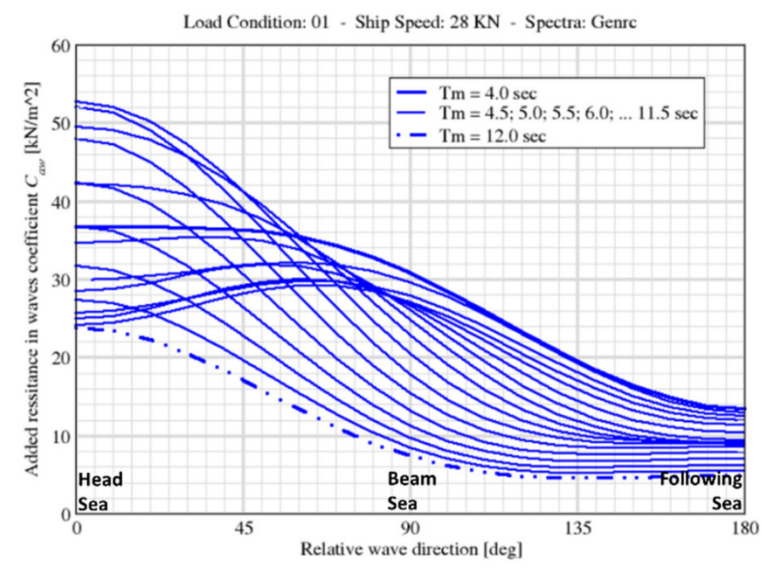

(b)

Figure 5. Added resistance in waves coefficient $C_{a w}$ computed, according to Equation (8), with "generic" unitary wave spectra, for different values of the average Wave Period $T_{m}$ and of the Average Wave Direction $D_{m}$ (waves from). The used ARO functions are those computed by PDSTRIP for the RoPax ship of Table 1, at the speed of (a) 20 knots and (b) 28 knots.

A further level of detail could be obtained by utilizing different parametric spectra for Wind Sea and Swells and pre-computing the respective $C_{a w}$ datasets. In this approach Equation (7) should be generalized by a sum extended to all the spectral partitions in the spectrum, with a similar form for each term, but with the total SWH substituted by the corresponding partition value multiplied by the respective $C_{a w}$. An approach of this kind could allow, if also in a simplified LUTs-based approximation, to account for the effects of spectra multimodality $[84,135,136,158-161]$ in fuel consumption computations. In the present work, some very preliminary tests have been performed. It must be pointed out that, in the case of not negligible overlapping of two or more spectral partition peaks, some kind of peaks deconvolution should be applied when summing the partitioned contributions, in order to avoid multiple accounting of the overlapping spectral peaks tails. This aspect will be better developed in further studies for a sound implementation into the prototype interface. A possible alternative under study is to precompute the integrals of Equation (8) with the most recurring spectral shapes emerging by a spectral wave climate elaboration [162-164], as well as by adopting suitable parametric functions for fitting wave climate spectral shapes [76,161].

The effects of marine currents can be included in the above treatment by introducing the implied kinematics, where needed. The ship speed along each leg of a route is defined w.r.t. the ground, i.e., it is a Speed Over Ground (SOG), so as marine currents and meteorological wind in metocean forecast data, while ship hydrodynamics data are dependent on STW. When marine currents are completely negligible it is possible to assume $S O G=S T W$, otherwise a kinematic transformation must be performed by a vector subtraction of the marine current vector from the SOG vector, in order to determine the STW and ship relative angles in each route leg.

The extension of the approach to other ship responses, besides the fuel consumption, is under study, in relation to the evaluation of seakeeping performance, comfort, structural stresses and safety indicators. Moreover, by pre-computing the suitable engine state and emission coefficients and storing them in respective LUTs, ship pollutant emissions could also be evaluated and included in the meteorological navigation process [165].

The availability of in-service data recording systems and big-data analysis techniques [24,166-169] could allow to better define, tune, and validate the numerical approaches to be applied in the pre-computing and "on-line performance evaluation" phases. Part of the algorithms have already been compared with in-service data, with encouraging results [51], but the next planned step will be a much more systematic process. A further relevant output of such an activity is expected to be the implementation of an algorithmic component capable of performing a continuous data driven models tuning. 
Preliminary analyses on this are considering a potentially fruitful and synergetic merging of the approaches here described with the frameworks of holistic ship design $[36,37,170]$, datadriven surrogate models $[171,172]$ and the ample world of digital twins, whose application in the marine context is growing at a more and more rapid pace $[42,113,173]$.

\section{Discussion of Illustrative Case Studies}

In this paragraph, examples of meteorological navigation, aided by the prototype interface, are described in order to illustrate its main functionalities. Realistic meteo-marine conditions are considered through metocean data from Consorzio LaMMA operational forecasting models. The character of the present study has to be considered as preliminary, and it is primarily devoted to the "meteorological navigation" component of the passage planning activity. As a consequence, the analysis is focused on illustrating metocean-related functionalities, while other elements pertaining to navigation rules and constraints are partly overlooked for the sake of exposition simplicity. Consequently, some details of the studied cases may result not completely realistic. In real applications, the ECDIS-like nature inherited from the original EPD system allows us to straightforwardly load and visualize Electronic Nautical Charts, giving the possibility to include in the analysis most of the needed data layers for a real and complete navigation activity. In this regard, other useful functions are potentially available from the original EPD system for the improvement of navigational safety, such as the possibility to exchange routes way points data with nearby ships and onshore ship traffic control centers (to reduce collision risk in high traffic areas, as well as through tactical routes suggestions) and dynamic no-go areas visualization (to reduce the risks of squat and grounding in shallow waters) [23,174].

\subsection{RoPax on a Short Route in Perturbed Metocean Conditions. Center-North Mediterranean Sea} (Sea of Corse)

As a first example, the analysis of a realistic voyage of a RoPax ship (design data: 1700 passengers, 500 cars, cruise speed 28 knots at $80 \%$ MCR; main particulars in Table 1) is considered, along a short Mediterranean route. For this ship, a complete LUTs dataset has been generated following the procedure described above. In the off-line computing process data and models from [51] have been used, where a tuning process for $R_{\text {hull }}$ had been performed by exploiting in-service recorded fuel consumption data. The resulting fuel consumption rate $F R$ LUT have been generated for two different propulsion configurations: with two and four engines, symmetrically active on the two shaft lines, equipped with CPP propellers. The four Wartsila 12V46C (11,700 kW each) medium speed four stroke diesel engines are capable of driving this ship up to 28 knots. The first configuration is available only for low values of STW, and very calm environmental conditions. In such cases, steaming with half the number of main engines active can allow some fuel saving (avoiding too low engine load). At higher speed and in heavy weather, only the four engines configuration is applicable. In both cases, if the active engines are not capable to cope with the total resistance implied by the environmental conditions encountered in a given route leg, the prototype interface stops computing and require the user to lower the ship speed (involuntary speed reduction) or switch to the four engines configuration. For the wind added resistance coefficient $C_{x}$ a simplified approach has been adopted trough data and models from [175]. Seakeeping computations have been performed by using the PDSTRIP software for the ARO function and the $C_{a w}$ LUTs for the added resistance, as described above. From the preliminary sensitivity analysis of optimal route solutions [47] emerged a greater relevance of the modeling details of the (usually) by far greater added resistance in waves w.r.t. wind added resistance modeling details. Hence, greater care has been put to generate the $C_{a w}$ LUTs.

In Figure 6a, the prototype system dialog window is shown where the ship loading and propulsion configurations can be defined, and through which the respective LUTs datasets can be imported by selecting the files where precomputed data have been stored. For each ship, it is possible to define multiple configurations, to be then selected trough the dialog window shown in the Figure 6a before performing each new fuel consumption computation. 
For the RoPax ship in this example, the two configured propulsion configurations (with two or four engines) are available.

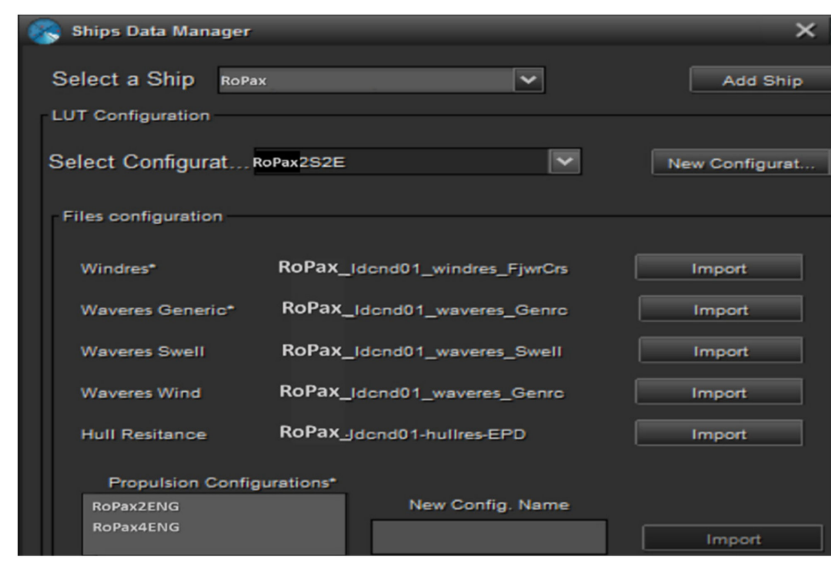

(a)

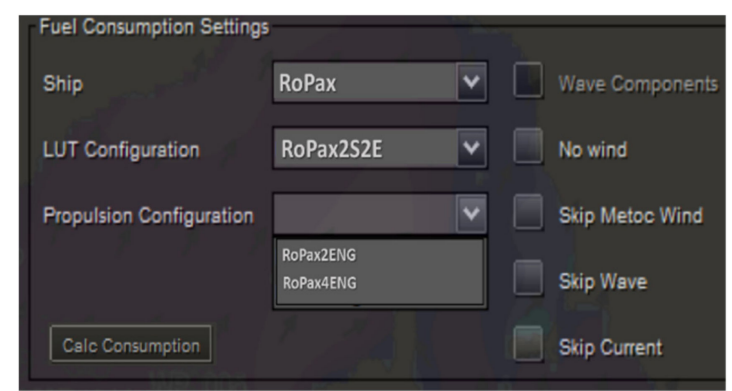

(b)

Figure 6. Dialog windows of the prototype system: (a) Settings for loading ship specific data from input LUTs files and defining different configurations for the same ship; (b) Selection of the ship configuration prior to activating each fuel consumption computation. The case study RoPax ship settings are visualized.

The speed profile along the route can be defined by assigning different speed values on each leg, and, correspondingly, different propulsion configurations can also be assigned to each leg. In addition to the $C_{a w}$ LUTs precomputed with the "generic" spectrum, it is also possible to utilize the Wave Components (wind sea and swell partitions)-based approach, but it is still in a preliminary testing phase. It is also possible to perform the computations by excluding one by one, or the whole set, of environmental conditions (selectors: skip wind, skip wave, skip current), in order to estimate ("by difference" in the results) the respective contribution to the fuel consumption.

In Figure 7, a recent voyage from Ajaccio (Corse Island) to Toulon (France) of a real RoPax ship is shown together with the corresponding speed profile, so as shown by the free online version of the Marine Traffic AIS data visualization and ship tracking system [176]. The ship is very similar to the modeled RoPax here studied; hence, this voyage has been simulated, and it is here analyzed.

In Figure 8, the same route (labeled as: "RoPax-22/04/2020") is shown, together with other route variants defined through the prototype interface. The "Shortest" route is the one usually adopted in case of fair-weather conditions and is a useful "baseline" term of comparison. The "RoPax-22/04/2020" route performs a zig-zag around the "Shortest" route, in order to avoid the worst conditions and improving passengers' comfort during the voyage. Usually, the areas with SWH greater than $2.5 \mathrm{~m}$ (red shading in the color-coding palette of the Sign. Wave Height) are avoided, if possible.

The "Variated" route has been defined by avoiding the zig-zag and steaming deeper towards North, but with the constraint of maintaining the length very similar to "RoPax22/04/2020". The "Variated Short" route has been obtained by shortening the "Variated" route, but trying to avoid areas with $H_{S}>2.5 \mathrm{~m}$. The selected ship speed (namely, SOG) profile along the "RoPax-22/04/2020" is very similar to the one of Figure 7. For the other routes, roughly equivalent speed profiles have been defined (keeping into account voyage timing). 


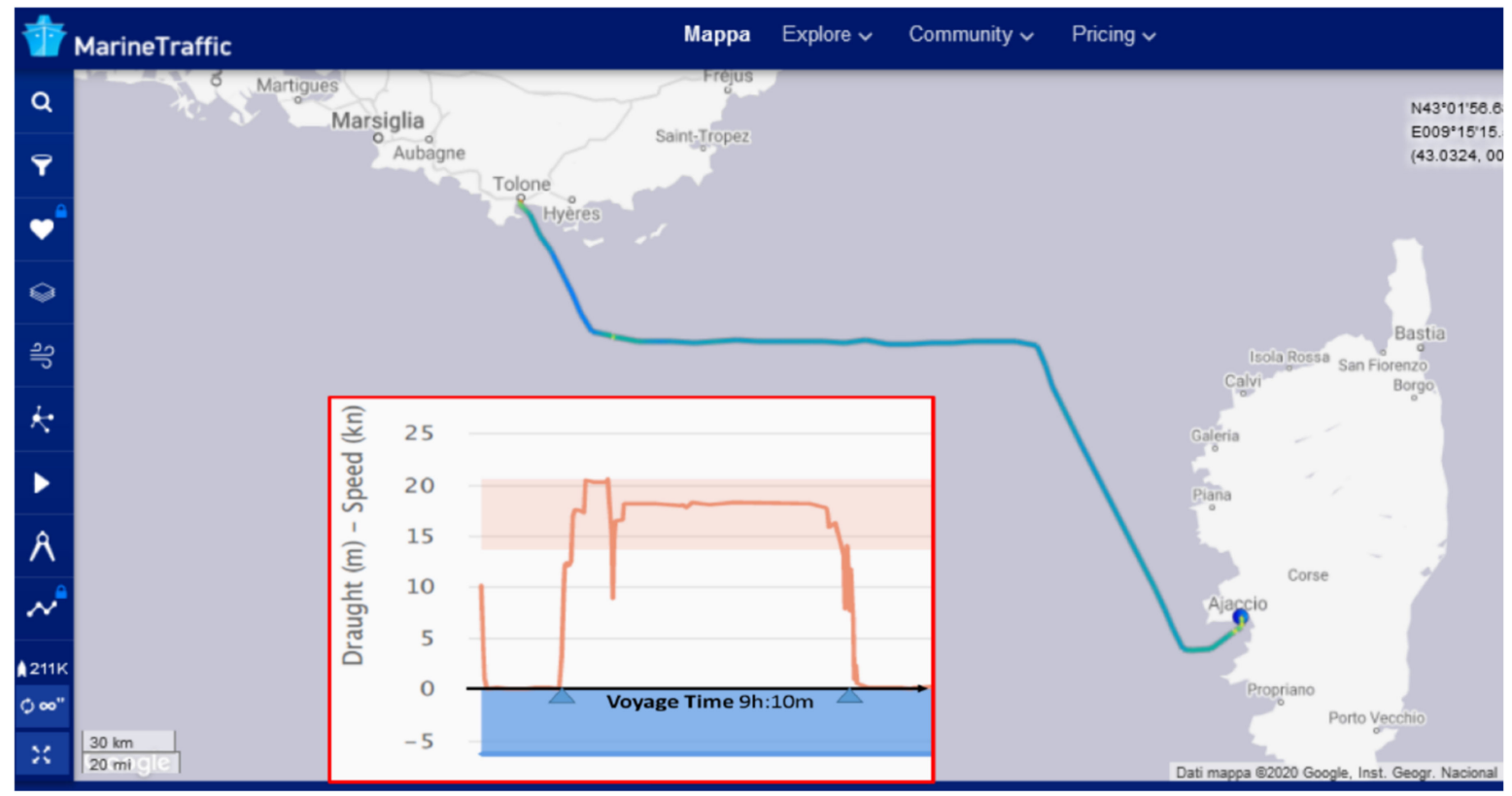

Figure 7. Map of the route of a real RoPax ship voyage, from Toulon (France) to Ajaccio (Corse). The corresponding speed profile is shown in the inserted box and by the colored shading along the route (from light green, for lower speed values, to bright blue, for higher speed values). Adapted from the free access web pages of Marine Traffic [166], with permission from Marine Traffic, 2020.

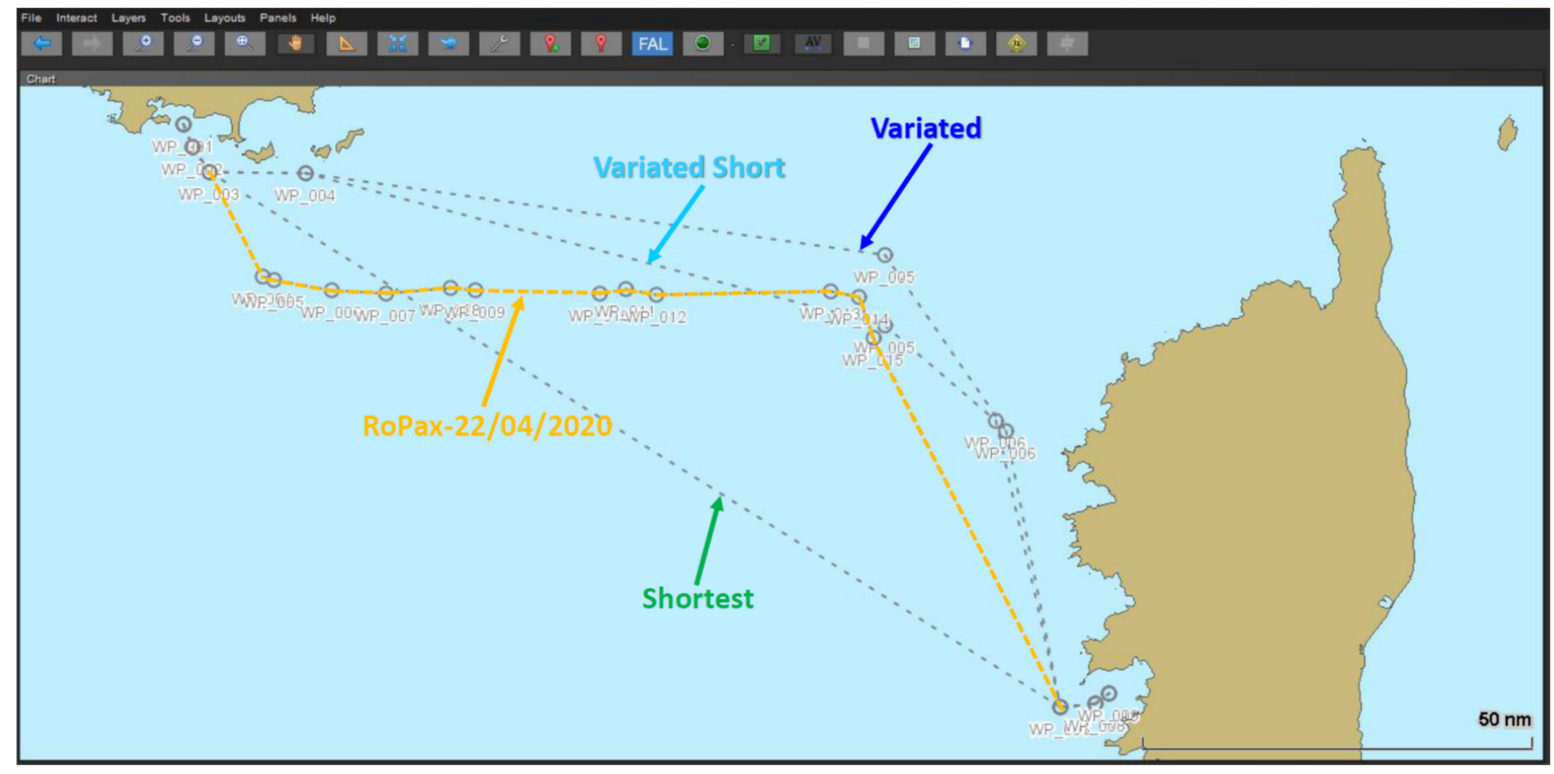

Figure 8. The route of Figure 7 labeled as "RoPax-22/04/2020" visualized through the prototype interface (evidenced in yellow), together with three variated routes labeled as "Shortest", "Variated", and "Variated Short") generated by using the prototype interface functionalities.

The "manual construction" of the variated routes is strongly aided by the capability of visualizing the maps at the nearest times of selectable points along the route. As an example in Figure 9, the map of $H_{s}$, together with Mean Wave Direction arrows and Wind Barbs, is shown at the time when the ship position along the four routes is the one shown by the yellow full arrow for the "RoPax-22/04/2020" route and by the blue full arrows for the other three. 


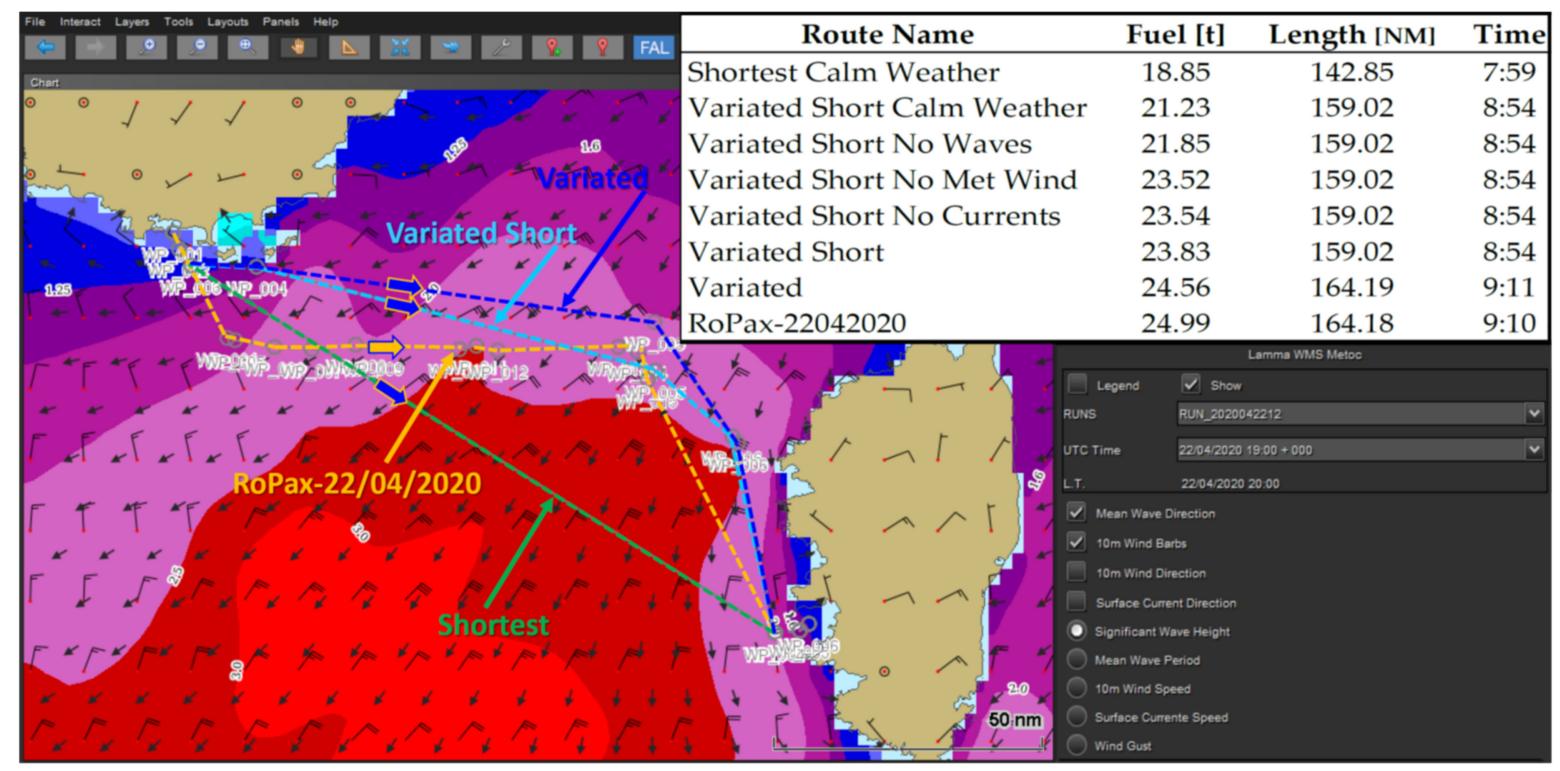

Figure 9. Visualization, through the prototype interface, of the SWH field map, together with Mean Wave Direction vectors and Wind Barbs. The superimposed bold yellow and blue arrows mark the position of the ship along the four studied routes. The "Routes sorting" table at top right shows the respective fuel consumption in tonnes. For some of them, the estimates obtained by skipping one by one and all the metocen contributions to resistance are also shown. The Time column shows voyage duration in hours and minutes (h: $\mathrm{mm}$ ).

Several fuel consumption computations have been performed by loading the ship specific LUTs and metocean data. In particular data from LaMMA forecasting system run of 22/04/2020 with initialization time at 12:00 UTC (a few hours before the ship time of departure) have been used. Some of the results are shown in the "Routes sorting table" shown in the top right panel of Figure 9.

The "RoPax-22/04/2020" estimated fuel consumption of nearly 25 tonnes is compared with several other variants. The estimated consumption for the "Variated" route is nearly half a ton less ( $2 \%$ of the total fuel), due to slightly better metocean conditions (route length is also slightly greater). The estimated consumption for the "Variated Short" route is one ton less $(4 \%)$, due to the combination of a moderate route length shortening and slightly better metocean conditions. This latter appears to be the best route; hence, it has been further analyzed by repeating the computations by alternatively switching off waves, wind, and currents effects, in order to estimate the respective effects on fuel consumption (about: $9 \%$ waves, $1 \%$ wind, $1 \%$ currents). The wind is not weak, but, in this case, its effects are weak (of the same order of currents effects), mainly due to nearly crosswind conditions for most of the voyage. The fuel consumption along the shortest route, without meteo-marine elements, i.e., the "Shortest Calm Weather" results, provides an estimate of the baseline fuel consumption for this voyage. It allows us to have a glimpse on the overall increase in fuel consumption due to both the direct bad weather effects and to the indirect effects related to the route elongation (e.g., compare with "Variated Short Calm Weather"), adopted in order to minimize dis-comfort and improve safety.

In the top right box of Figure 10, the results of a further analysis are summarized. For the routes: "RoPax-22/04/2020", "Variated Short", and "Shortest", the fuel consumption has been estimated by using metocean data from six hourly spaced consecutive runs of LaMMa forecast system: 21/04/2020 with initialization at 18 UTC, and the runs of $22 / 04 / 2020$ with initialization at $00,06,12$ UTC, respectively. The results pattern is essentially the same for all three routes: for each one of them the consumptions from the "oldest" forecasts are very similar, while the results from the last run (i.e., 22/04/2020, with init. at 12) are shifted by about 1 tonne to lower values. The visualization, along the shortest route, of metocean data from such a forecast run and from the one initialized 
at 00 , as reported in the map of Figure 10 (red dots in the upper right panel), show that the overall metocean data pattern is very similar (metocean arrows from the two forecasts are nearly superimposed), with the exception of the coastal areas near Toulon. The forecast initialized at 12 is instead characterized by a lower intensity of the adverse weather conditions. This justifies reduced fuel consumption estimates from the most recent forecast. Due to the coherence and persistence of the overall spatial pattern, the ordering of the fuel consumption estimates along the different routes in this case is not influenced by forecast variability.

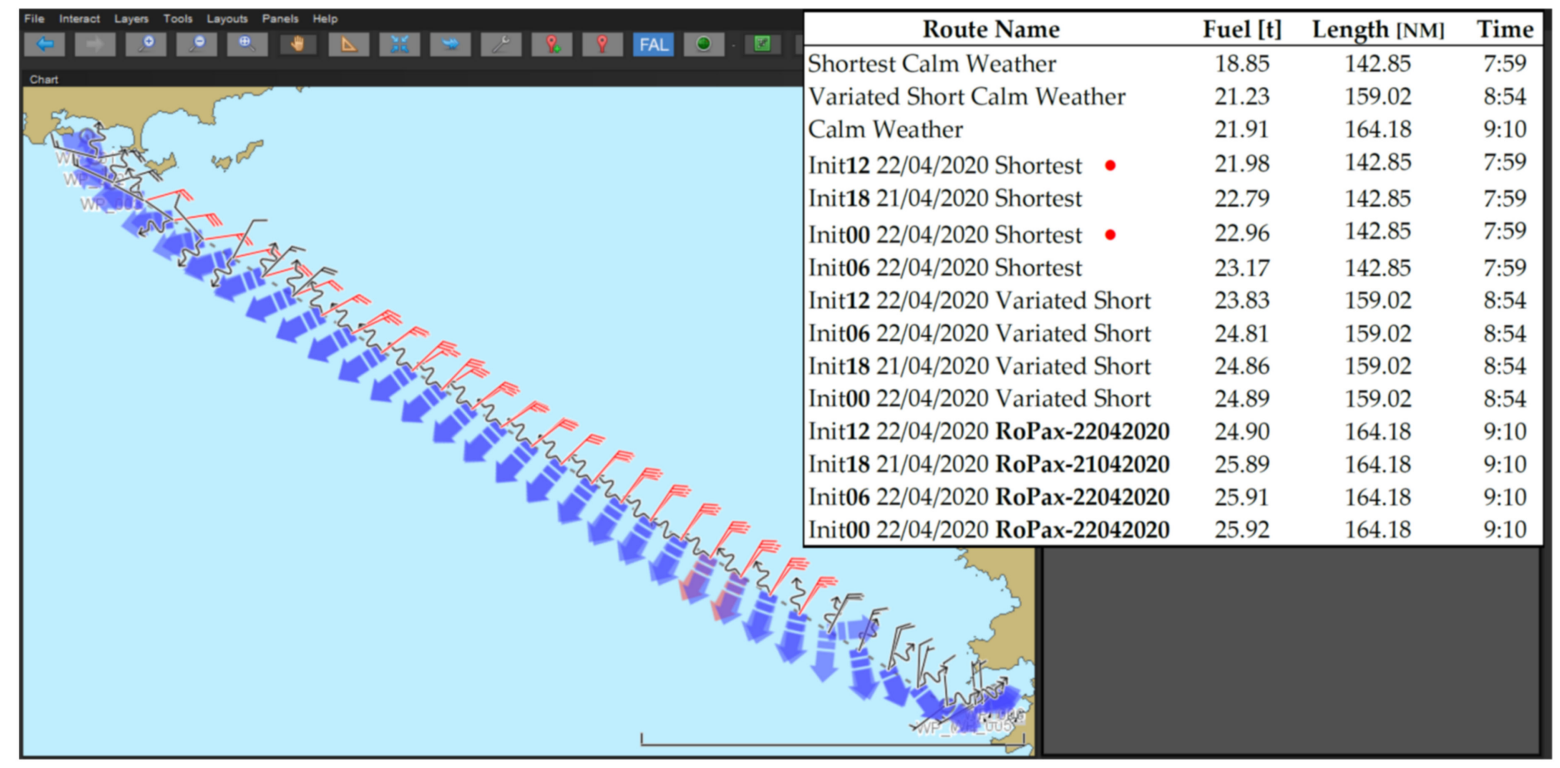

Figure 10. In the map to the left: visualization, through the prototype interface, of metocean data along the shortest route. The data from the forecast runs initialized on 22/04/2020 at 00 and at 12 UTC are superimposed to graphically check their concordance. The "Routes sorting" table on the top right, shows the fuel consumption estimates, for each one of the four routes of Figures 8 and 9, as estimated by alternatively using data from four consecutive models runs and in calm weather. The Time column shows voyage duration in hours and minutes (h:mm).

\subsection{S175 Containership on a Medium Length Route in Heavy Weather. Eastern Mediterranean Sea}

As a second case study a simplified numerical model of the S175 containership [155] is considered (main particulars in Table 1), having performed an engine-hull-propeller matching with a single shaft line, a FPP propeller, and a single MAN B\&W 6S50MC-C8 low speed two-stroke diesel engine.

The selected engine for this purely numerical (and not completely realistic) test model has a very poor weather margin and is able to drive the ship only up to $20 \mathrm{knots}$, in completely calm weather. In further developments of the study, investigations will be performed by adding auxiliary sails to "help" this "not so powerful" engine. In moving to more realistic ship models, the issue of "sufficient of propulsion power" in relation with safety constraints must be carefully evaluated, as investigated in the SHOPERA Project [177]. Longer Mediterranean routes have been analyzed by considering a voyage from Port Said (Egypt) to La Valletta (Malta). The time of departure is supposed to be 18/09/2020 at 01:00 UTC, the ship SOG is supposed to be constant at 14 knots. The meteomarine conditions are characterized by the development of a (real) relevant event of heavy weather. A Tropical Like Cyclone (TLC) or Medicane (for Mediterranean hurricane) [178] forms in the area and, during its evolution, it unavoidably impacts the ship voyage. TLC formation is not frequent, but, when it happens, its effects are potentially very relevant; moreover, the occurrence of such systems is growing in the Mediterranean basin, probably due to climate change [179]. 
In Figure 11, the TLC evolution is shown by metocean maps generated through the prototype interface, based on LaMMA forecast data from the run of 18/09/2020 with initialization at 00 UTC (Run00). The validity time of each map is reported in the respective top right box. The SWH is visualized with superimposed Average Wave Direction and surface Wind Barbs. Panel (a): after its formation and intensification in the Ionian Sea, a quite intense TLC moves towards Grece. Panel (b): after the landfall, the TLC undergoes a temporary attenuation. Panel (c): re-intensification of the TLC when returning over the sea in the SW of Greece. Then, it continues its track passing South of Crete, rapidly moving towards the Eastern Mediterranean Basin.

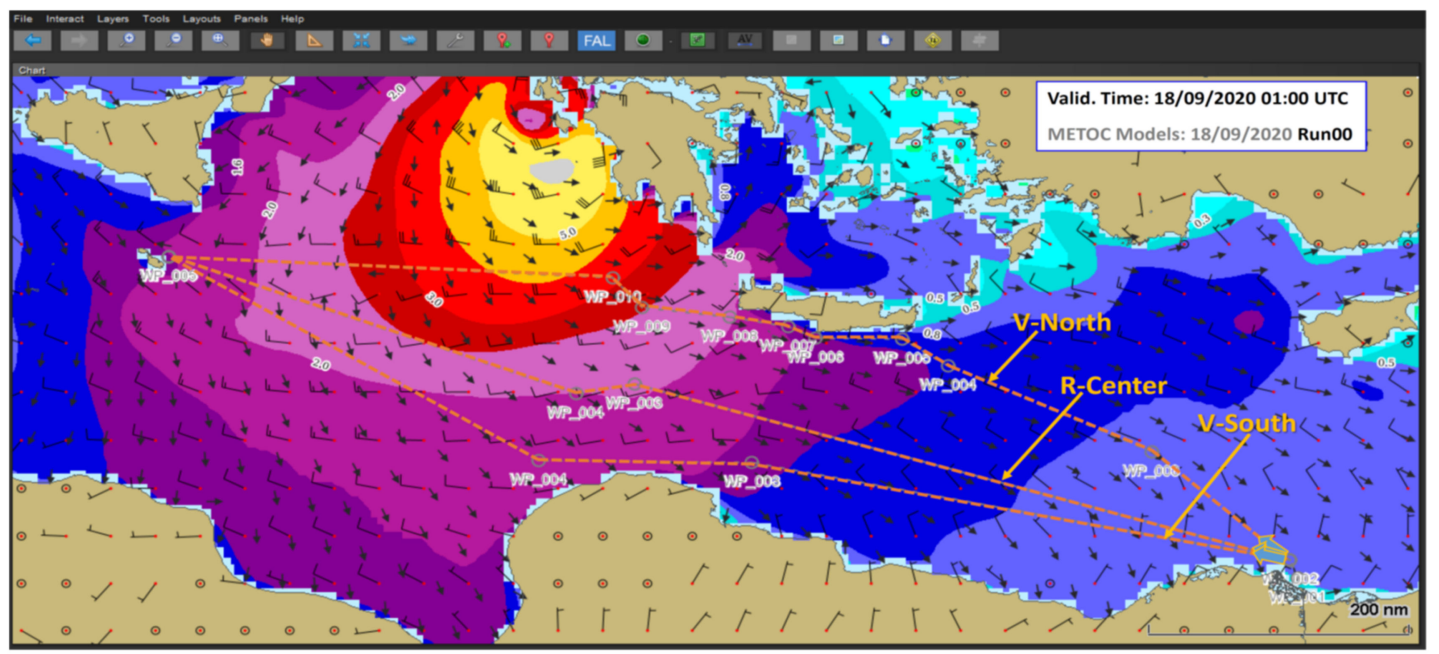

(a)

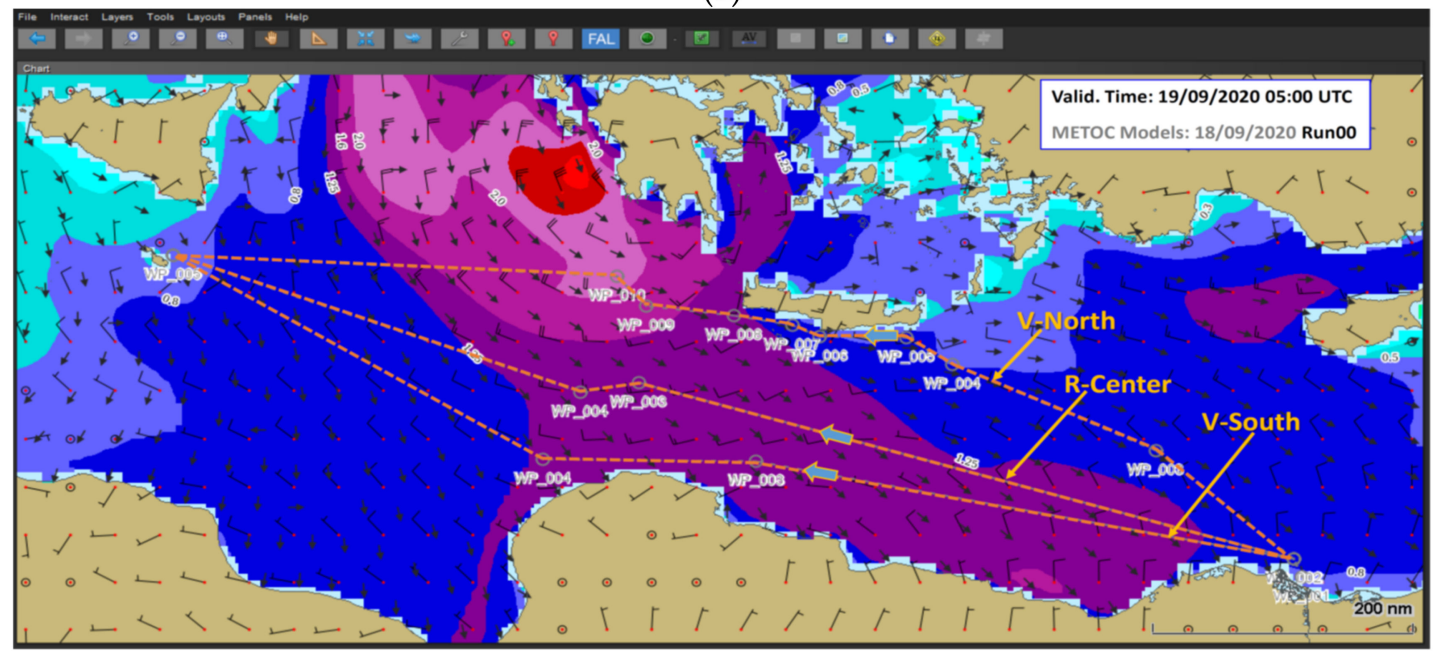

(b)

Figure 11. Cont. 


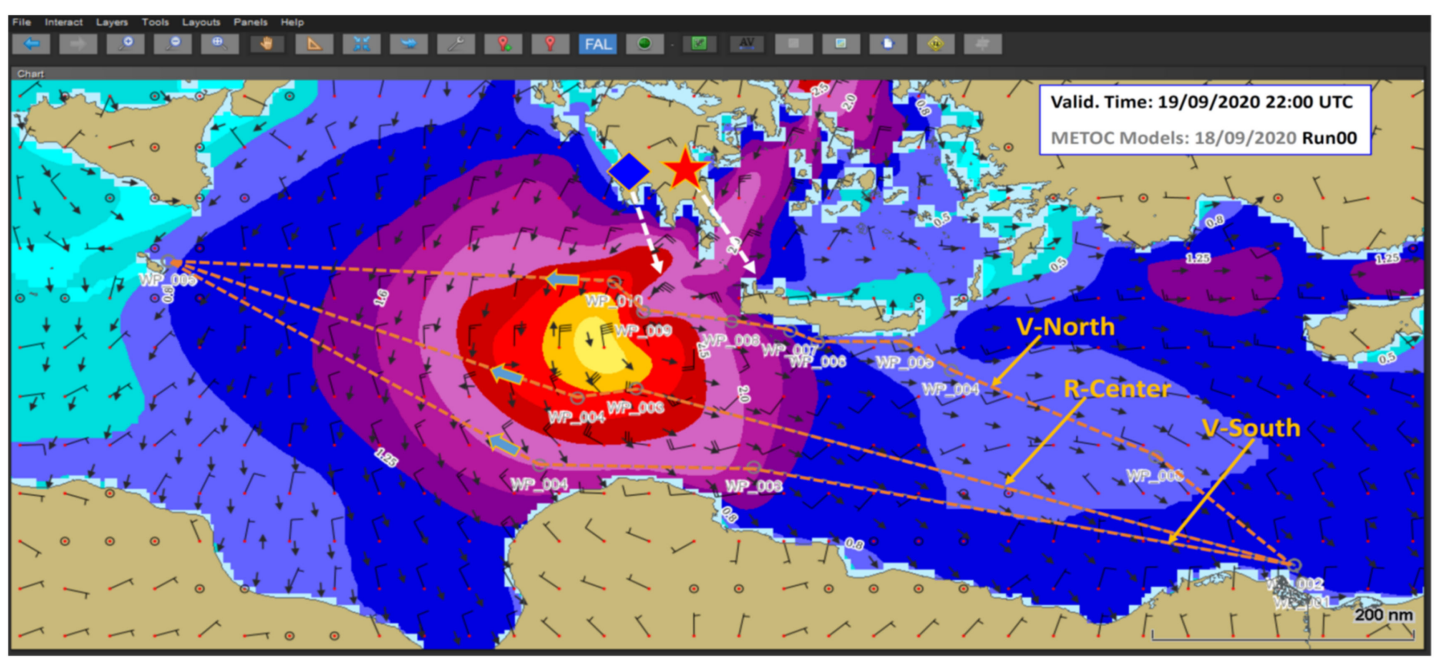

(c)

\begin{tabular}{|lccc|lccc|}
\hline \multicolumn{1}{|c}{ Route Name } & Fuel [t] & Length [NM] & Time & Route Name & Fuel [t] & Length [NM] & Time \\
\hline R-Center Calm Weather & 42.51 & 930.00 & 2d 18:25 & V-North & 50.30 & 948.30 & 2d 19:44 \\
V-North Calm Weather & 43.33 & 948.30 & 2d 19:44 & R-Center & 53.90 & 930.00 & 2d 18:25 \\
V-South Calm Weather & 43.35 & 948.34 & 2d 19:44 & V-South & 56.06 & 948.34 & 2d 19:44 \\
\hline
\end{tabular}

(d)

Figure 11. Panels (a)-(c) prototype interface showing: SWH, Average Wave Direction, and Wind Barbs maps for three times during the simulated Port Said-La Valletta voyage. Three alternative routes are shown. Blue arrows indicate ship positions at the maps' validity times. Panel (d) fuel estimates: left in calm weather, right with metocean data. The Time columns show voyage duration in days, hours, and minutes (<days $>$ d hh:mm).

Three alternative routes, all with departure time 18/09/2020 at 01:00 UTC are overlaid on metocenan conditions in Figure 11. Route $R$-Center: is the shortest central route; Route $V$-North: is the Northern variation; Route $V$-South: is the Southern variation. The two variated routes have roughly the same length. For all the routes, a deviation is needed to avoid the worst conditions in the central part of the voyage, as illustrated in panel (b). In this case of a containership, a less stringent constraint on $H_{S}$ is applied, but the poor weather margin of the propulsive engine still forces a route diversion to avoid the heaviest weather. The respective positions of the ship are shown by blue full arrows in Figure 11a-c. In Figure 11 bottom panel (d), the "Route sorting" tables from the prototype system are shown, to compare the fuel consumption along the three routes, computed with metocean data from the LaMMA forecast data of 18/09/2020 Run00 (right), and the respective consumption in calm weather conditions (left). The least consuming route is the Northern variation, exploiting some favorable conditions. In the initial legs from Port Said to Crete, milder conditions are encountered with respect to the other two routes. In the central part of the voyage, the shielding effect of Crete is relevant. Moreover, in proximity of the low-pressure center, the Northern variation encounters a less extended heavy weather area, thanks to combined effects of the proximity of the low-pressure center and of the screening and attenuation by the surrounding coastlines. In this area, the shortest route, running in between the other two, is heavily impacted on a larger portion of its track. In addition, more prevailing crosswind conditions induce a smaller contribution from wind resistance on the Northern variation, while the other two, and especially the Southern variation, are more affected by head wind conditions.

As an example, in Figure 12, the spectral partitions analysis for the two locations indicated by the blue diamond and the red star in Figure 11c are shown at the same time of the map (19/09/2020 22:00 UTC). For the blue diamond site, Figure 12a shows a relevant wind sea component from NE, due to the strong winds related to the actual position of the TLC center of low pressure, and a weaker but not negligible swell component from NW. This swell component has a very long period of $9 \mathrm{~s}$ and has been generated by the strong winds of the TLC in its past positions at the north of the area. For the red star 
site, Figure $12 \mathrm{~b}$ shows a swell component, with a not so high period of $7.5 \mathrm{~s}$, coming from the $\mathrm{W}$ and related to the TLC peripheral medium strength wind condition, and a weak wind sea component from ESE, due to light near coastal winds NW of Crete. The possibility to compute the encounter values of the peak periods $T_{p e}$ for each one of the spectral components allows us to estimate the consequences of Doppler effect due to the selected ship speed and allows us to better test possible route variations. Examples are shown, in Figure 12, for two ship speed configurations tested during the route variations analysis in this case study. In correspondence of the blue diamond point, the selected ship speed has the effect of relevantly reducing the perceived period of the Swell 1 component, being in nearly Head Sea configuration, while, for the Wind Sea, the reduction is smaller because it is nearly in beam sea condition. In correspondence of the red star point, the peak period of the Swell 1 component undergoes a similar reduction, while the Wind Sea component undergoes a relevant increase of the perceived period because it is in proximity of surfriding conditions (i.e., nearly zero encounter frequency, due to proximity of ship speed and wave phase speed).

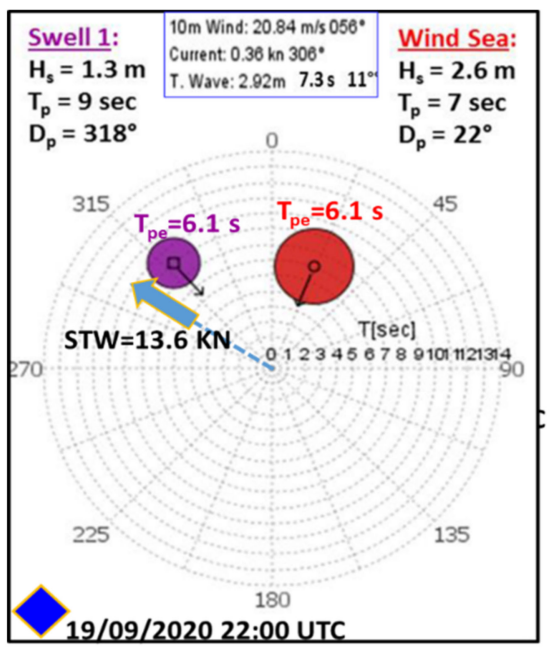

(a)

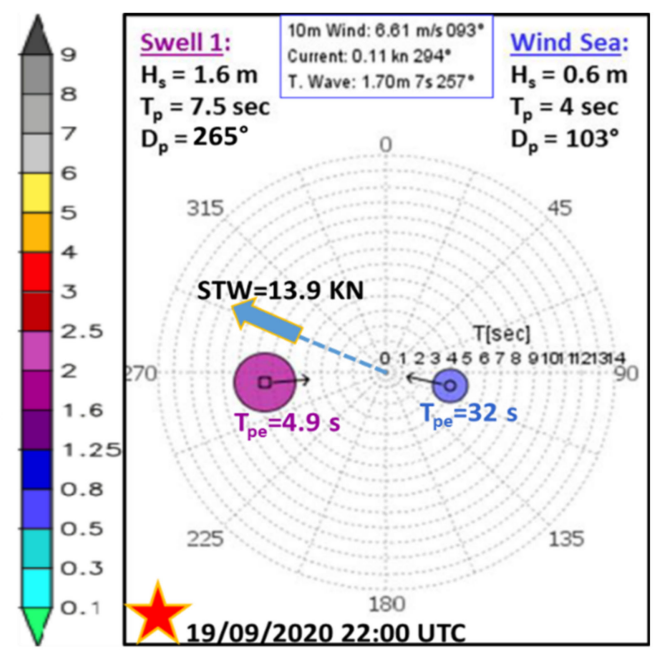

(b)

Figure 12. Spectral partitions visualization for 19/09/2020 at 22:00 UTC seaway state in correspondence of the two locations indicated in Figure 13 with: (a) blue diamond, (b) red star. In addition, shown are the encounter period values for all the wave components, for two, respectively, tested values of the ship speed.

After a detailed analysis, some further variations to the Northern route V-North of Figure 11 have been considered, as shown in Figure 13 (now labeled with V2-North). The route legs in the South of Crete have been brought farther South from Crete coast, to shorten a little but still exploiting milder conditions in the area. The way points in the north of the blue diamond point of Figure 11c have been moved more North, to search for less intense conditions. The consequent elongation of the route is (partly) compensated by the shortening in the South of Crete. The net result of the changes is a further reduction in the estimated fuel consumption along the northern variated route. Finally, a new northern variated route $(\mathrm{V}$-NCrete) has been defined in order to better exploit the milder conditions in the first leg from Port Said to Crete and in passing North of it. This latter change increases the route length a bit, but it allows us to fully exploit the wider area of mild conditions in the North of Crete. As a consequence, this new route is the least consuming one, as shown by the new fuel consumption estimates reported in the "Routes sorting" panel visualized in the top right of Figure 13. Moreover, it is also a safer route, due to the relevant shielding effect of Crete with respect to the harsh weather conditions caused by the evolution of the TLC system in the area. For this route, a further element is worth to be considered: due to the longer (and safer) track in the north of Crete, the ship enters at later times in the area 
(West of Crete) more affected by heavy weather, caused by the TLC. At such a later time, the TLC has already moved further South-East, and the ship finds there already attenuated heavy weather conditions.

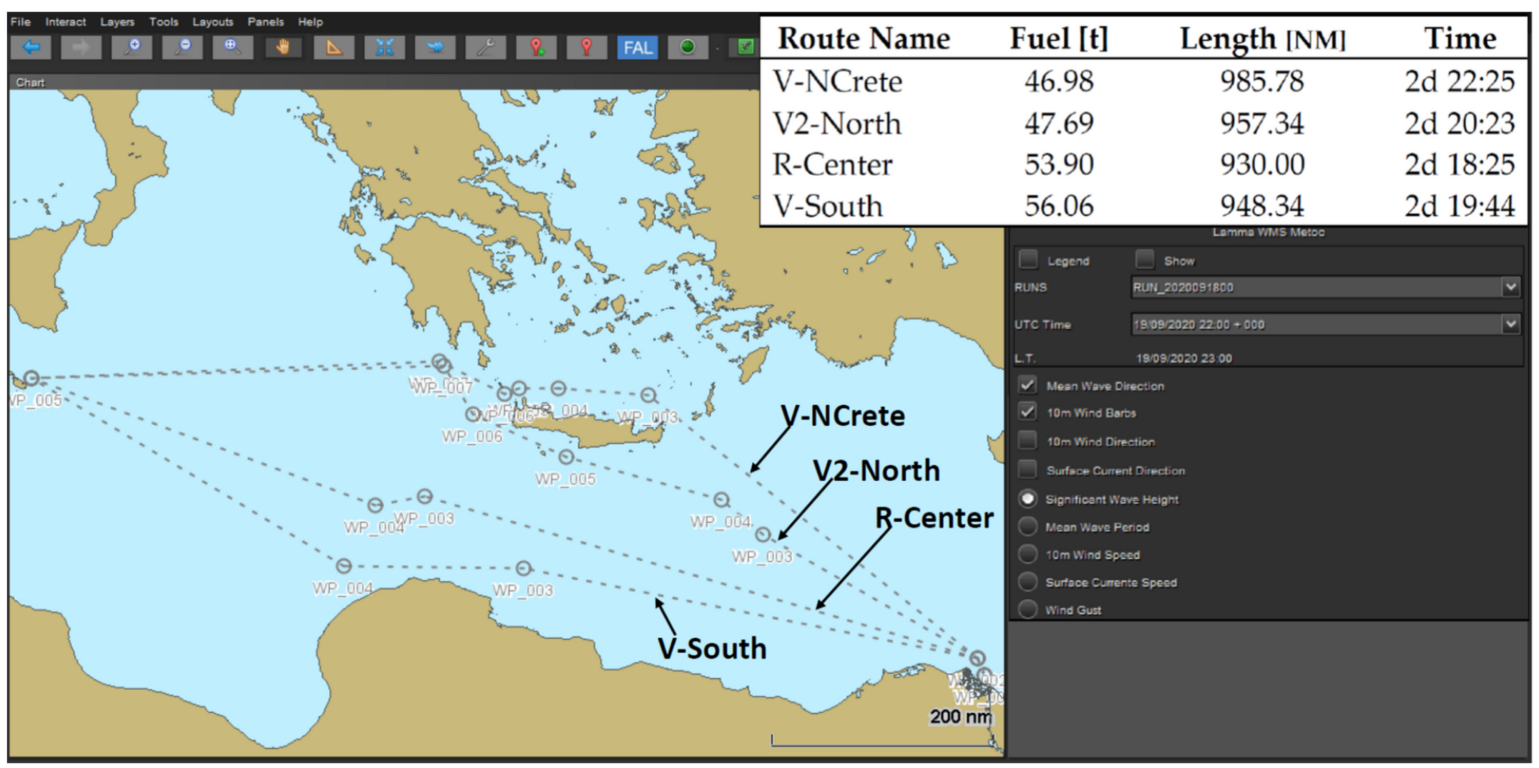

Figure 13. New analysis of four alternative routes from Port Said to La Valletta. The central route and the southern variation as before. The northern variation and the new one passing North of Crete are new variations. In the top right panel, the Routes sorting table is shown with fuel consumption estimates for these four routes. The Time column shows voyage duration in days, hours, and minutes (<days $>$ d hh:mm).

\section{Conclusions}

A prototype system for performing meteorological navigation tasks has been implemented by exploiting an ECDIS-like Graphical User Interface. The first components implemented are mainly focused on fuel consumption performance evaluation. The resulting prototype system allows the uploading and visualization of metocean data, the consequent computation of fuel consumption along each analyzed route, and the evaluation of the encountered meteo-marine conditions on each route way point in a totally integrated framework. This allows us to "effectively and deeply dig inside" the various layers of available metocean forecast data regarding atmospheric and marine conditions and evaluating their effects on ship performance indicators. The approaches adopted for the present implementation are described, and further alternatives are shortly reviewed. GIS-based visualization of forecast fields has been exploited, and an innovative visualization tool for wave forecast data, based on spectral partitions, has been implemented and tested, while, for a quick numerical estimation of ship performance, an approach has been implemented that allows us to perform the heaviest aero-hydrodynamic computations in off-line mode, storing the results in fast access look-up tables. The analysis of two case studies, performed by the use of the prototype system, is summarized with the goal of illustrating the implemented functionalities. The prototype system is still in a preliminary version, and its potential improvements and extensions are also discussed. In particular, some of the planned additions and modifications are: a more systematic validation-tuningimprovement of the ship modeling algorithms, consequent to the integration with a reliable in-service data recording and processing system; the extension to a wider set of performance indicators, not only oriented to propulsive fuel consumption; the addition of the capability to work with EPS (Ensemble Prediction System) data; and the addition of the capability to trigger numerical route optimization algorithms, to be implemented as integrated components of the system. These are some of the main components that should improve the prototype interface towards a powerful and comprehensive meteorological 
navigation tool, potentially applicable both for single ship navigation and on-shore single ship and fleet monitoring and management, and also integrated with other operational guidance systems.

Author Contributions: Conceptualization, A.O. (Andrea Orlandi); methodology, A.O. (Andrea Orlandi) and A.C.; software, A.C.; validation, A.O. (Andrea Orlandi) and A.C.; formal analysis, A.O. (Andrea Orlandi); investigation, A.O. (Andrea Orlandi); resources, A.O. (Andrea Orlandi), R.M. and F.P.; data curation, A.O. (Andrea Orlandi), R.M. and F.P.; writing-original draft preparation, A.O. (Andrea Orlandi).; writing-review and editing, A.O. (Andrea Orlandi), and A.C.; visualization, A.O. (Andrea Orlandi), A.C.; supervision, A.O. (Andrea Orlandi); project administration, A.O. (Andrea Orlandi) and A.O. (Alberto Ortolani); funding acquisition, A.O. (Alberto Ortolani). All authors have read and agreed to the published version of the manuscript.

Funding: This work has been partially developed under the PROFUMO Demonstration project, funded by the ESA Artes IAP programme.

Institutional Review Board Statement: Not Applicable.

Informed Consent Statement: Not Applicable.

Data Availability Statement: Not Applicable.

Conflicts of Interest: The authors declare no conflict of interest.

\section{References}

1. Stopford, M. Maritime Economics, 3rd ed.; Routledge: London, UK, 2008.

2. Christiansen, M.; Fagerholt, K.; Nygreen, B.; Ronen, D. Maritime Transportation. In Handbooks in Operations Research and Management Science; Barnhart, C., Laporte, G., Eds.; Elsevier: Amsterdam, The Netherlands, 2007; Volume 14, pp. 189-284.

3. Windek, V. A Liner Shipping Network Design. Routing and Scheduling Considering Environmental Influences. Ph.D. Thesis, Hamburgh University, Hamburgh, Germany, 2013.

4. Weintrit, A. Marine Navigation and Safety of Sea Transportation; Taylor \& Francis Group: London, UK, 2009.

5. Bouman, E.A.; Lindstad, E.; Rialland, A.I.; Strømman, A.H. State-of-the-art technologies, measures, and potential for reducing GHG emissions from shipping. A review. Transp. Res. Part D 2017, 52, 408-442. [CrossRef]

6. Smith, T.W.P.; O'Keeffe, E.; Aldous, L.; Agnolucci, P. Assessment of Shipping's Efficiency Using Satellite AIS Data; UCL Energy Institute: London, UK, 2013.

7. DNV-GL. Maritime Forecast to 2050; Energy Transition Outlook: Hovik, Norway, 2020.

8. Trancossi, M. What price of speed? A critical revision through constructal optimization of transport modes. Int. J. Energy Environ. Eng. 2016, 7, 425-448. [CrossRef]

9. Psaraftis, H.N. Speed Optimization vs. Speed Reduction: The Choice between Speed Limits and a Bunker Levy. Sustainability 2019, 11, 2249. [CrossRef]

10. Meyer, J.; Stahlbock, R.; Voß, S.; Voss, S. Slow Steaming in Container Shipping. In Proceedings of the 201245 th Hawaii International Conference on System Sciences, Maui, HI, USA, 4-7 January 2012; pp. 1306-1314.

11. IMO. Just in Time Arrival Guide: Barriers and Potential Solutions; IMO GloMEEP Project Coordination Unit: London, UK, 2020.

12. Panagakos, G.; Pessôa, T.D.S.; Dessypris, N.; Barfod, M.B.; Psaraftis, H.N. Monitoring the Carbon Footprint of Dry Bulk Shipping in the EU: An Early Assessment of the MRV Regulation. Sustainability 2019, 11, 5133. [CrossRef]

13. Allal, A.A.; Mansouri, K.; Youssfi, M.; Qbadou, M. Ship Operational Measures Implementation's Impact on Energy-Saving and GHG Emission. In Proceedings of the Advanced Intelligent Systems for Sustainable Development (AI2SD'2019): Advanced Intelligent Systems Applied to Energy, Marrakech, Morocco, 8-11 July 2019; Volume 2, pp. 307-319.

14. Canbulat, O.; Aymelek, M.; Turan, O.; Boulougouris, E. A Bayesian Belief Network Model for Integrated Energy Efficiency of Shipping. In Maritime Women: Global Leadership; Springer: Cham, Switzerland, 2018; pp. 257-273.

15. Campana, E.F.; Ciappi, E.; Bertram, V. New IT Technologies for a Sustainable Blue Growth. In Proceedings of the 12th Symposium on High-Performance Marine Vehicles, Cortona, Italy, 12-14 October 2020.

16. Matsuo, K.; Tanigawa, F. On Future Strategy and Technology Roadmap of Maritime Industry. In Proceedings of the 12th Symposium on High-Performance Marine Vehicles, Cortona, Italy, 12-14 October 2020.

17. Procee, S. Considerations for a Novel Augmented Reality Display on the Ship's Bridge. In Proceedings of the 12th Symposium on High-Performance Marine Vehicles, Cortona, Italy, 12-14 October 2020.

18. IMO e-Navigation. Available online: www.imo.org/en/OurWork/Safety/Navigation/Pages/eNavigation.aspx (accessed on 22 September 2020).

19. Patraiko, E.D. Introducing the e-Navigation Revolution. Seaways. Int. J. Naut. Inst. Lond. 2007.

20. Weintrit, A. Development of the IMO e-Navigation Concept. Common Maritime Data Structure. In Modern Transport Telematics; Mikulski, J., Ed.; Springer: Berlin/Heidelberg, Germany, 2011; Volume 239. 
21. IALA e-Navigation Portal. Available online: www.iala-aism.org/technical/e-navigation/ (accessed on 22 September 2020).

22. Lind, M.; Bergmann, M.; Hägg, M.; Karlsson, F.; Siwe, U.; Watson, R. Sea Traffic Management-The Route to the Future. In Proceedings of the 17th Conference on Computer and IT Applications in the Maritime Industries (COMPIT), Pavone, Italy, 14-16 May 2018.

23. STM Project. Available online: www.seatrafficmanagement.info (accessed on 22 September 2020).

24. Koga, S. Major Challenges and Solutions for Utilizing Big Data in the Maritime Industry. Master's Thesis, World Maritime University, Malmö, Sweden, 2015.

25. Simonsen, M.H.; Larsson, E.; Mao, W.; Ringsberg, W. State-of-the-art within ship weather routing. In Proceedings of the ASME 2015, 34th International Conference on Ocean, Offshore and Arctic Engineering, St. John's, NL, Canada, 31 May-5 June 2015.

26. Walther, L.; Rizvanolli, A.; Wendebourg, M.; Jahn, C. Modeling and Optimization Algorithms in Ship Weather Routing. Int. J. e-Navig. Marit. Econ. 2016, 4, 31-45. [CrossRef]

27. Wiśniewski, B.; Szymański, M. Comparison of ship performance optimization systems and the bon voyage onboard routing system. Sci. J. Zesz. Nauk. Marit. Univ. Szczec. 2016, 47, 106-115.

28. Perera, L.P.; Guedes Soares, C. Weather routing and safe ship handling in the future of shipping. Ocean Eng. 2017, 130, 684-695. [CrossRef]

29. Lópeza, J.M.L.; Calabriaa, L.; Tannera, M.; Martíneza, J.; Giméneza, J.A. Vessl as a tool for macro-analyses at European level. STM Validation Project results calculated by the use of Short Sea Shipping data mining. In Proceedings of the 8th Transport Research Arena TRA 2020, Helsinki, Finland, 27-30 April 2020.

30. Takashima, K.; Mezaoui, B.; Shoji, R. On the fuel saving operation for coastal merchant ships using weather routing. Int. J. Mar. Nav. Saf. Sea Transp. 2009.

31. Michaelides, M.P.; Herodotou, H.; Lind, M.; Watson, R.T. Port-2-Port communication enhancing Short Sea Shipping performance: The case study of Cyprus and the Eastern Mediterranean. Sustainability 2019, 11, 1912. [CrossRef]

32. Martìnez de Osès, F.X.; Castells, M. Wave height incidence on Mediterranean Short Sea Shipping routes. Tethys $2006,3,3-8$.

33. Wärtsilä Smart Voyage Optimisation. Available online: www.wartsila.com/smart-voyage (accessed on 10 October 2020).

34. NAVTOR Weather Routeing. Available online: www.navtor.com/weatherservices.html (accessed on 10 October 2020).

35. JRC Japan. J-Marine Cloud. Weather Routing and Smart Ship Service. Available online: www.jmarinecloud.com/eng/corporation/ routing_pro (accessed on 16 November 2020).

36. Papanikolaou, A. Holistic ship design optimization: Merchant and naval ships. Ship Sci. Technol. 2011, 5, 9. [CrossRef]

37. Papanikolaou, A.; Flikkema, M.; Harries, S.; Marzi, J.; Le Néna, R.; Torben, S.; Yrjänäinen, A. Tools and Applications for the Holistic Ship Design. In Proceedings of the 8th Transport Research Arena, Helsinki, Finland, 27-30 April 2020.

38. Guangrong, Z. Intelligent Design and Operation of Ship Energy Systems Combining Big Data and AI. In Proceedings of the 17th Conference on Computer and IT Applications in the Maritime Industries (COMPIT), Pavone, Italy, 14-16 May 2018.

39. Mizythras, P.; Pollalis, C.; Boulougouris, E.; Theotokatos, G. A novel decision support methodology for oceangoing vessel collision avoidance. Ocean Eng. 2021, 230, 109004. [CrossRef]

40. Tillig, F.; Mao, W.; Ringsberg, J.W. Systems Modelling for Energy-Efficient Shipping; Chalmers University of Technology, Department of Shipping and Marine Technology, Division of Marine Technology: Göteborg, Sweden, 2015; ISSN 1652-9189.

41. Grieves, M.; Vickers, J. Digital Twin: Mitigating Unpredictable, Undesirable Emergent Behavior in Complex Systems. In Transdisciplinary Perspectives on Complex Systems; Kahlen, F.-J., Flumerfelt, S., Alves, A., Eds.; Springer: Berlin/Heidelberg, Germany, 2017.

42. Smogeli, Ø. The Internet of Big Things. Digital Twins at Work in Maritime and Energy; DNV-GL Feature: Olso, Norway, 2017.

43. Nikolopoulos, L.; Boulougouris, E. A novel method for the holistic, simulation driven ship design optimization under uncertainty in the big data era. Ocean Eng. 2020, 218, 107634. [CrossRef]

44. Brinkmann, M.; Hahnn, A.; Hjøllo, B.A. Physical Testbed for Highly Automated and Autonomous Vessels. In Proceedings of the 16th Conference on Computer and IT Applications in the Maritime Industries (COMPIT), Hamburg, Germany, 15-17 May 2017.

45. Chen, M.-L.; Chesneau, L.S. Heavy Weather Avoidance and Route Design; Paradise Cay Publications, Inc.: Arcata, CA, USA, 2008.

46. Orlandi, A.; Benedetti, R.; Mari, R.; Costalli, L. Sensitivity Analysis of Route Optimization Solutions on Different Computational Approaches for Powering Performance in the Seaway. In Proceedings of the 17th Conference on Computer and IT Applications in the Maritime Industries (COMPIT), Pavone, Italy, 14-16 May 2018.

47. Kalnay, E. Atmospheric Modeling, Data Assimilation and Predictability; Cambridge University Press: Cambridge, UK, 2003.

48. Hoffschildt, M.; Bidlot, J.-R.; Hansen, B.; Janssen, P.A.E.M. Potential Benefit of Ensemble Forecasts for Ship Routing; ECMWF Research Department Technical Memorandum: Reading, UK, 1999.

49. Chu, P.C.; Miller, S.E.; Hansen, J.A. Fuel-saving ship route using the Navy's ensemble meteorological and oceanic forecasts. J. Def. Model. Simul. Appl. Methodol. Technol. 2015, 12, 41-56.

50. Skoglund, L.; Kuttenberger, J.; Rosen, A.; Ovegard, E. A comparative study of deterministic and ensemble weather forecasts for weather routing. J. Mar. Sci. Technol. 2015, 20, 429-441. [CrossRef]

51. Orlandi, A.; Pasi, F.; Capecchi, V.; Coraddu, A.; Villa, D. Powering and seakeeping forecasting for energy efficiency: Assessment of the fuel savings potential for weather routing by in-service data and ensemble prediction. In Proceedings of the IMAM 2015 Conference Proceedings, Towards Green Marine Technology and Transport, Pula, Croatia, 21-24 September 2015.

52. Coiffier, J. Fundamentals of Numerical Weather Prediction; Cambridge University Press: Cambridge, UK, 2011. 
53. Roger, A.; Pielke, S. Mesoscale Meteorological Modeling; Academic Press: Cambridge, MA, USA, 2002 ; Volume 78.

54. Komen, G.J.; Cavaleri, L.; Donelan, M.; Hasselman, K.; Hasselman, S.; Janssen, P.A.E. Dynamics and Modelling of Ocean Waves; Cambridge University Press: Cambridge, UK, 1994.

55. WISE Group; Cavaleri, L.; Alves, J.-H.G.M.; Ardhuin, F.; Babanin, A.; Banner, M.; Belibassakis, K.; Benoit, M.; Donelan, M.; Groeneweg, J.; et al. Wave modelling. The state of the art. Prog. Oceanogr. 2007, 75, 603-674.

56. Ardhuin, F. Ocean. Waves in Geosciences; Laboratoire d'Oceanographie Physique et Spatiale: Brest, France, 2018.

57. Miller, N.M. Numerical Modeling of Ocean Circulation; Cambridge University Press: Cambridge, UK, 2007.

58. Kampf, J. Advanced Ocean. Modelling Using Open-Source Software; Springer: Dordrecht, The Netherlands, 2010.

59. Valcke, S.; Balaji, V.; Craig, A.; DeLuca, C.; Dunlap, R.; Ford, R.W.; Jacob, R.; Larson, J.; O’Kuinghttons, R.; Riley, G. Coupling technologies for Earth System Modelling. Geosci. Model. Dev. 2012, 5, 1589-1596. [CrossRef]

60. Ličer, M.; Smerkol, P.; Fettich, A.; Ravdas, M.; Papapostolou, A.; Mantziafou, A.; Strajnar, B.; Cedilnik, J.; Jeromel, M.; Jerman, J.; et al. Modeling the ocean and atmosphere during an extreme bora event in northern Adriatic using one-way and two-way atmosphere-ocean coupling. Ocean Sci. 2016, 12, 71-86. [CrossRef]

61. COAMPS Overview. Available online: www.nrlmry.navy.mil/coamps-web/web/view (accessed on 23 October 2020).

62. Network Common Data Form (NetCDF). Available online: www.unidata.ucar.edu/software/netcdf (accessed on 23 October 2020).

63. WMO Manual on Codes. Available online: www.wmo.int/pages/prog/www/WMOCodes.html (accessed on 23 October 2020).

64. Consorzio LaMMA. Available online: www.lamma.rete.toscana.it (accessed on 23 October 2020).

65. Skamarock, W.C.; Klemp, J.B. A Time-split non-hydrostatic atmospheric model for weather research and forecasting applications. J. Comput. Phys. 2008, 227, 3465-3485. [CrossRef]

66. Weather Research and Forecasting Model. Available online: www.mmm.ucar.edu/weather-research-and-forecasting-model (accessed on 24 October 2020).

67. Global Forecast System (GFS). Available online: www.ncdc.noaa.gov/data-access/model-data/model-datasets/global-forcastsystem-gfs (accessed on 24 October 2020).

68. WAVEWATCH III R Development Group (WW3DG). User Manual and System Documentation of WAVEWATCH III R Version 6.07; Tech. Note 333; NOAA/NWS/NCEP/MMAB: College Park, MD, USA, 2019. Available online: https:/ / raw.githubusercontent. com/wiki/NOAA-EMC/WW3/files/manual.pdf (accessed on 5 May 2021).

69. Copernicus Marine. Available online: marine.copernicus.eu (accessed on 24 October 2020).

70. NEMO Community Ocean Model. Available online: https://www.nemo-ocean.eu (accessed on 5 January 2021).

71. OPeNDAP, Advanced Software for Remote Data Retrieval. Available online: https:/ / www.opendap.org/ (accessed on 12 January 2021).

72. The Open Geospatial Consortium (OGC). Available online: www.ogc.org/about (accessed on 3 December 2020).

73. Wang, D.W.; Hwang, P.A. An Operational Method for Separating Wind Sea and Swell from Ocean Wave Spectra. J. Aerosp. Technol. 2001, 18.

74. Portilla, J.; Ocampo-Torres, F.J.; Monbaliu, J. Spectral Partitioning and Identification of Wind Sea and Swell. J. Aerosp. Technol. 2008, 26. [CrossRef]

75. Tracy, B.E.-M.; Devaliere, J.L.; Hanson, T.; Nicolini, T.; Tolman, H.L. Wind sea and swell delineation for numerical wave modeling. In Proceedings of the 10th International Workshop on Wave Hindcasting and Forecasting, Oahu, HI, USA, 11-16 November 2007.

76. Boukhanovsky, A.V.; Guedes Soares, C. Modelling of multipeaked directional wave spectra. Appl. Ocean Res. 2009, 31, 132-141. [CrossRef]

77. IMO. Guidance to the Master for Avoiding Dangerous Situations in Following and Quartering Seas; Circular MSC/707; International Maritime Organization: London, UK, 1995.

78. IMO. Revised Guidance to the Master for Avoiding Dangerous Situations in Adverse Weather and Sea Conditions; Circular MSC.1/1228; International Maritime Organization: London, UK, 2007.

79. Schiller, P. Analysis of the Possibility to Avoid Maritime Accidents by the Application of MSC.1/Circ. 1228 and MSC/Circ. 707. Master's Thesis, Hamburg University of Technology, Institute of Ship Design and Ship Safety, Hamburg, Germany, 2010.

80. Bačkalov, I.; Bulian, G.; Cichowicz, J.; Eliopoulou, E.; Konovessis, D.; Leguen, J.-F.; Roséng, A.; Themelis, N. Ship Stability, Dynamics and Safety: Status and Perspectives. Ocean Eng. 2016, 116, 312-349. [CrossRef]

81. Ludeno, G.; Orlandi, A.; Lugni, C.; Brandini, C.; Soldovieri, F.; Serafino, F. X-Band marine radar system for high-speed navigation purposes: A test case on a cruise ship. IEEE Geosci. Remote Sens. Lett. 2014, 11, 244-248. [CrossRef]

82. Fucile, F. Deterministic Sea Wave and Ship Motion Forecasting: From Remote Wave Sensing to Prediction Error Assessment. Ph.D. Thesis, Engineering and Architecture Department, Trieste, Italy, 2016.

83. Nielsen, U.D.; Jensen, J.J. A novel approach for navigational guidance of ships using onboard monitoring systems. Ocean Eng. 2011, 38, 444-455. [CrossRef]

84. Montazeri, N. Estimation of Waves and Ship Responses Using On-Board Measurements. DCAMM Special Report, No. S202. Ph.D. Thesis, Technical University of Denmark, Lyngby, Denmark, 2016.

85. Ariffin, A.; Laurens, J.M.; Mansor, S. Real-Time Evaluation of Second Generation Intact Stability Criteria; Smart Ship Technology: London, UK, 2016.

86. Peters, W.; Belenky, V.; Bassler, C.; Spyrou, K.; Umeda, N.; Bulian, G.; Altmayer, B. The second generation intact stability criteria: An overview of development. Trans. Soc. Nav. Archit. Mar. Eng. 2011, 119. 
87. Petacco, N.; Gualeni, P. IMO Second Generation Intact Stability Criteria: General Overview and Focus on Operational Measures. J. Mar. Sci. Eng. 2020, 8, 494. [CrossRef]

88. Carlton, J.S. Marine Propellers and Propulsion; Elsevier: Amsterdam, The Netherlands, 2007.

89. Vettor, R.; Tadros, M.; Ventura, M.; Guedes Soares, C. Influence of main engine control strategies on fuel consumption and emissions. In Proceedings of the 4th International Conference on Maritime Technology and Engineering (MARTECH 2018), Lisbon, Portugal, 7-9 May 2018.

90. Szelangiewicz, T.; Żelazny, K. Mathematical model for calculating fuel consumption in real effect weather for a vehicle vessel. Multidiscip. Asp. Prod. Eng. 2019, 2, 367-374. [CrossRef]

91. Lewis, E.V. Resistance, Propulsion and Vibration. In Principles of Naval Architecture; SNAME Editions: Jersey City, NJ, USA, 1990; Volume 2.

92. Birk, L. Fundamentals of Ship Hydrodynamics. Fluid Mechanics, Ship Resistance and Propulsion; Wiley: Hoboken, NJ, USA, 2019.

93. Harvald, S. Resistance and Propulsion of Ships; John Wiley \& Sons: New York, NY, USA, 1983.

94. Reichel, M.; Minchev, A.; Larsen, N.L. Trim Optimisation-Theory and Practice. Trans. Nav. 2014, 83. [CrossRef]

95. Bertram, V. Trim Optimisation—Don't Blind me with Science! The Naval Architect, Royal Institution of Navl Architects: London, UK, 2014.

96. Perera, L.P.; Mo, B.; Kristjánsson, L.A. Identification of Optimal Trim Configurations to improve Energy Efficiency in Ships. In Proceedings of the 10th IFAC Conference on Manoeuvring and Control of Marine Craft (MCMC2015), Copenhagen, Denmark, 24-26 August 2015; pp. 267-272.

97. Psaraftis, H.N. Speed optimization versus speed reduction: Are speed limits better than a bunker levy? Marit. Econ. Logist. 2019, 21, 524-542. [CrossRef]

98. ITTC. ITTC Recommended Procedures and Guidelines. Testing and Extrapolation Methods Resistance, Resistance Test. In Proceedings of the 23rd International Towing Tank Conference (ITTC'02), Venice, Italy, 8-14 September 2002.

99. ITTC. ITTC Recommended Procedures and Guidelines. Analysis of Speed/Power Trial Data. In Proceedings of the 23rd International Towing Tank Conference (ITTC'02), Venice, Italy, 8-14 September 2002.

100. ISO. ISO 15016:2015, Ship and Marine Technology. Guidelines for the Assessment of Speed and Power Performance by Analysis of Speed Trial Data; ISO: Genava, Switzerland, 2015.

101. Van den Boom, H. Sea Trial Analysis JIP. Recommended Analysis of Speed Trials; MARIN: Wageningen, The Netherlands, 2006.

102. Holtrop, J. A statistical re-analysis of resistance and propulsion data. Int. Shipbuild. Prog. 1984, $31,363$.

103. Holtrop, J.; Mennen, G. An approximate power prediction method. Int. Shipbuild. Prog. 1982, 29, 166-170. [CrossRef]

104. Hollenbach, K. Estimating resistance and propulsion for single-screw and twinscrew ships in the preliminary design. In Proceedings of the 10th International Conference on Computer Applications in Shipbuilding (ICCAS'99), Cambridge, MA, USA, 7-11 June 1999.

105. Matulja, D.; Dejhalla, R. A comparison of a ship hull resistance determined by different methods. Eng. Rev. 2007, 27.

106. ITTC. ITTC Recommended Procedures and Guidelines. Practical Guidelines for Ship CFD Applications. In Proceedings of the 23rd International Towing Tank Conference, Venice, Italy, 2-9 June 2011.

107. Bernitsas, M.M.; Ray, D.; Kinley, P. Kt, Kq and Efficiency Curves for the Wageningen B-Series Propellers; The University of Michigan: Ann Arbor, MI, USA, 1981.

108. Dangn, J.; van den Boom, H.; Ligtelijn, J. The Wageningen C- and D-Series Propellers. In Proceedings of the FAST Conference, San Jose, CA, USA, 12-15 February 2013.

109. Bulten, N.W.; Stoltenkamp, P.W.; Van Hooijdonk, J.J. Efficient Propeller Designs Based on Full Scale CFD Simulations; Wärtsilä: Drunen, The Netherlands, 2014.

110. Villa, D.; Gaggero, S.; Gaggero, T.; Tani, G.; Vernengo, G.; Viviani, M. An efficient and robust approach to predict ship selfpropulsion coefficients. Appl. Ocean Res. 2019, 92. [CrossRef]

111. Giorgiutti, Y.; Rezende, F.; Van, S.; Monteiro, C.; Preterote, G. Impact of Fouling on Vessel's Energy Efficiency. In Proceedings of the 25 Congresso Nacional de Transporte Aquaviário, Construção Naval e Offshore, Rio de Janeiro, Brasil, 10-12 November 2014.

112. Coraddu, A.; Oneto, L.; Baldi, F.; Cipollini, F.; Atlar, M.; Savio, S. Data-driven ship digital twin for estimating the speed loss caused by the marine fouling. Ocean Eng. 2019, 186. [CrossRef]

113. Lewis, E.V. Motions in Waves and Controllability. In Principles of Naval Architecture; SNAME Editions: Alexandria, VA, USA, 1990; Volume 3.

114. Blendermann, W. Book review: Practical Ship and Offshore Structure Aerodynamics. Ship Technol. Res. 2014, 61, 110-111. [CrossRef]

115. Haddara, M.; Soares, C.G. Wind loads on marine structures. Mar. Struct. 1999, 12, 199-209. [CrossRef]

116. Watanabe, I.; Van Nguyen, T.; Miyake, S.; Shimizu, N.; Ikeda, Y. A study on reduction of air resistance acting on a large container ship. In Proceedings of the 8th Asia-Pacific Workshop on Marine Hydrodynamics in Naval Architecture, Ocean Technology and Constructions, Hanoi, Vietnam, 20-23 September 2016.

117. Wang, W.; Wu, T.; Zhao, D.; Guo, C.; Luo, W.; Pang, Y. Experimental-numerical analysis of added resistance to container ships under presence of wind-wave loads. PLoS ONE 2019, 14, e0221453. [CrossRef] [PubMed]

118. Saydam, A.Z.; Taylan, M. Evaluation of wind loads on ships by CFD analysis. Ocean Eng. 2018, 158, 54-63. [CrossRef] 
119. Szelangiewicz, T.; Zelazny, K. Calculation of mean long-term service speed of transport ships, Part I. Pol. Marit. Res. 2006, 4, 23-31.

120. Bertram, V. Some heretic thoughts on ISO19030. In Proceedings of the HullPIC Conference, Ulrichshusen, Germany, 27-29 March 2017.

121. Hagiwara, H. Weather Routing of (Sail-Assited) Motor Ships. Ph.D. Thesis, Delft University of Technology, Delft, The Netherlands, 1989.

122. Lu, R.; Ringsberg, J.W. Ship energy performance study of three wind assisted ship propulsion technologies including a parametric study of the Flettner rotor technology. Ships Offshore Struct. 2019, 15. [CrossRef]

123. SAIL. Final Report. Roadmap for Sail Transport: Engineering; SAIL: Leeuwarden, The Netherlands, 2015.

124. IWSA. International Wind Ship Assiciation. Available online: http:/ / wind-ship.org/en/grid-homepage (accessed on 2 April 2021).

125. Bordogna, G.; van der Kolk, N.; Mason, J.; Bonello, J.-M.; Vrijdag, A. Wind-assisted ship propulsion performance prediction, routing and economic analysis-A corrected case study. In Proceedings of the RINA Wind Propulsion Conference, London, UK, 15-16 October 2019.

126. Schinas, O. Reduction of GHG Emissions from Ships. Wind Propulsion Solutions; Report Submitted to IMO MEPC 75/INF.26; IMO: London, UK, 2020.

127. DNV-GL Industry Insights. Available online: www.dnvgl.com/expert-story/maritime-impact/Wind-assisted-propulsion-cancut-fuel-costs-and-emissions.html (accessed on 27 October 2020).

128. Hoffmeister, H. Wind Propulsion-Assessment, Certification and Classification Services. In Proceedings of the 12th Symposium on High-Performance Marine Vehicles, Cortona, Italy, 15-16 October 2020.

129. ABS Press Release. ABS-MARIN JIP on Wind Propulsion Technologies. Available online: ww2.eagle.org/en/news/press-room/ abs-and-marin-launch-wind-propulsion-technology-jip.html (accessed on 27 October 2020).

130. Hagemeister, N.; Hensel, T.; Jahn, C. Performance Prediction and Weather Routing of Wind Assisted Ships. In Proceedings of the 12th Symposium on High-Performance Marine Vehicles, Cortona, Italy, 15-16 October 2020.

131. Hollenbach, U.; Hansen, H.; Hympendahl, O.; Reche, M.; Ruiz Carrio, E. Wind Assisted Propulsion Systems as Key to Ultra Energy Efficient Ships. In Proceedings of the 12th Symposium on High-Performance Marine Vehicles, Cortona, Italy, 15-16 October 2020.

132. Faltinsen, O.M. Sea Loads on Ships and Offshore Structures; Cambridge University Press: Cambridge, UK, 1998.

133. Coraddu, A.; Figari, M.; Savio, S.; Villa, D.; Orlandi, A. Integration of Seakeeping and Powering Computational Techniques with Meteo-Marine Forecasting Data for In-Service Ship Energy Assessment, Sustainable Maritime Transportation and Ex-Ploitation of Sea Resources; Soares, G., Peña, L., Eds.; Taylor \& Francis Group: London, UK, 2013.

134. Orlandi, A. Integration of Meteo-Marine Forecast Data with Ship Seakeeping and Powering Computational Techniques. Ph.D. Thesis, University of Genoa, Genoa, Italy, 2012.

135. Spentza, E.; Besio, G.; Mazzino, A.; Gaggero, T.; Villa, D. A Ship Weather Routing Tool for Route Evaluation and Selection: Influence of The Wave Spectrum; Taylor \& Francis: Milton, UK, 2017.

136. Orlandi, A.; Bruzzone, D. Numerical Weather and Wave Prediction Models for Weather Routing, Operation Planning and Ship Design: The Relevance of Multimodal Wave Spectra; Taylor\& Francis Group: London, UK, 2011.

137. Reed, M. The Second Order Steady Force and Moment on a Ship Moving in an Oblique Seaway—Revisited, Internal Report; David Taylor Research Center: Bethesda, MD, USA, 2004.

138. Alexandersson, M. A Study of Methods to Predict Added Resistance in Waves. Master's Thesis, KTH Centre for Naval Architecture, Stockholm, Sweden, 2009.

139. Vitali, N.; Prpić-Oršić, J.; Guedes Soares, C. Uncertainties related to the estimation of added resistance of a ship in waves. In Proceedings of the 3rd International Conference on Maritime Technology and Engineering, Lisbon, Portugal, 4-6 July 2016.

140. Bertram, V.; Couser, P. Computational methods for seakeeping and added resistance in waves. In Proceedings of the 13th International Conference on Computer and IT Applications in the Maritime Industries (COMPIT'14), Redworth, UK, 12-14 May 2014.

141. Bertram, V. Practical Ship Hydrodynamics; Butterworth-Heinemann: Oxford, UK, 2011.

142. Price, W.G.; Bishop, R.E.D. Probabilistic theory of Ship Dynamics; Chapman and Hall: London, UK, 1974.

143. Dern, J.-C.; Quenez, J.-M.; Wilson, P. Compendium of Ship Hydrodynamics. Practical Tools and Applications; Les Presses de 1'ENSTA: Paris, France, 2015.

144. Liu, S.; Papanikolaou, A.; Zaraphonitis, G. Prediction of added resistance of ships in waves. Ocean Eng. 2011, 38, 641-650. [CrossRef]

145. Liu, S.; Shang, B.; Papanikolaou, A.; Bolbot, V. Improved formula for estimating added resistance of ships in engineering applications. J. Mar. Sci. Appl. 2016, 15, 442-451. [CrossRef]

146. Hizir, O.; Kim, M.; Turan, O.; Day, A.; Incecik, A.; Lee, Y. Numerical studies on non-linearity of added resistance and ship motions of KVLCC2 in short and long waves. Int. J. Nav. Archit. Ocean Eng. 2019, 11, 143-153. [CrossRef]

147. Hulsbergen, S.A. Prediction of the Added Resistance in Waves Using CFD. Master's Thesis, Delft University of Technology, Delft, The Netherlands, 2019.

148. Van den Boom, H.; Huisman, H.; Mennen, F. New Guidelines for Speed/Power Trials: Level Playing Field Established for IMO EEDI. In SWZ/Maritime; MARIN: Wageningen, The Netherlands, 2013; pp. 1-11. Available online: https://repository.tudelft.nl/ islandora/object/uuid:aaae5227-4333-4dfe-8e6d-9b766397954b (accessed on 5 May 2021).

149. Grin, R. On the prediction of wave-added resistance with empirical methods. J. Ship Prod. Des. 2015, 31, 181-191. [CrossRef] 
150. Kim, K.-S.; Roh, M.-I. ISO 15016:2015-based method for estimating the fuel oil consumption of a ship. J. Mar. Sci. Eng. 2020,8 , 791. [CrossRef]

151. Lewandowski, M. The Dynamics of Marine Craft: Maneuvering and Seakeeping; World Scientific: Singapore, 2004.

152. Bertram, V.; Veelo, B.; Söding, H. Program PDSTRIP: Public Domain Strip Method, Software Documentation. 2006. Available online: https:/ / www.researchgate.net/publication/262413711_Development_of_a_Freely_Available_Strip_Method_for_Seakeeping (accessed on 5 May 2021).

153. Graf, K.; Pelz, M.; Bertram, W.; Soding, H. Added resistance in seaways and its impact on yacht performance. In Proceedings of the the 18th Chesapeake Sailing Yacht Symposium, Annapolis, MD, USA, 2-3 March 2007.

154. Böese, P. Eine einfache methode zur berechnung der widerstands derhohung eines schies im seegang. J. Schistechnik Ship Technol. Res. 1970, 258, 1-18.

155. ITTC. S-175 comparative model experiments-Report of the Seakeeping Committee. In Proceedings of the 18th ITTC International Towing Tank Conference, Kobe, Japan, 18-24 October 1987.

156. Matulja, D.; Sportelli, M.; Prpic-Orsic, J.; Guedes Soares, C. Methods for Estimation of Ships Added Resistance in Regular Waves. Brodograndja 2011, 3, 259-264.

157. DNV-GL. Recommended Practice. Modelling and Analysis of Marine Operations; DNV-RP-H103, Edition July 2017; DNV: Bærum, Norvey, 2017.

158. Lawford, R.; Bradon, J.; Barberon, T.; Camps, C.; Jameson, R. Directional wave partitioning and its application to the structural analysis of an FPSO. In Proceedings of the International Conference on Offshore Mechanics and Arctic Engineering, Estoril, Portugal, 15-20 June 2008; pp. 333-341.

159. Melger, F. Dangerous Seas from an Installation Contractor's Perspective; Melger Heerema Marine Contractors: Leiden, The Netherlands, 2011.

160. Ruggeri, F.; Watai, R.; Rosetti, G.; Tannuri, E.; Nishimoto, K. The development of ReDRAFT ${ }^{\circledR}$ system in Brazilian Ports for safe underkeel clearance computation. In Proceedings of the PIANC-World Congress, Panama City, Panama, 7-12 May 2018.

161. Vogel, M.; Hanson, J.; Fan, S.; Forristall, G.Z.; Li, Y.; Fratantonio, R.; Jonathan, P. Efficient environmental and structural response analysis by clustering of directional wave spectra. In Proceedings of the Offshore Technology Conference, Houston, TX, USA, 2-5 May 2016.

162. Boukhanovsky, A.; Lopatoukhin, L.; Guedes Soares, C. Spectral wave climate of the North Sea. Appl. Ocean Res. 2007, $29,146-154$. [CrossRef]

163. Sánchez-Arcilla, A.; Gonzalez-Marco, D.; Bolanos, R. A review of wave climate and prediction along the Spanish Mediterranean coast. Nat. Hazards Earth Syst. Sci. 2008, 8, 1217-1228. [CrossRef]

164. Boukhanovsky, A.V.; Chernyshyova, E.S.; Ivanov, S.V.; Lopatoukhin, L.I. New generation of wind and wave climate handbooksGuide to naval architect and for offshore activity. In Marine Technology and Engineering; Guedes Soares, C., Garbatov, Y., Foneseca, N., Texeira, A.P., Eds.; Taylor \& Francis Group: London, UK, 2011.

165. Orlandi, A.; Guarnieri, F.; Busillo, C.; Calastrini, F.; Coraddu, A. Air quality simulations and forecasting of along-route ship emissions in realistic meteo-marine scenarios. In Proceedings of the NAV 2018: 19th International Conference on Ship and Maritime Research, Trieste, Italy, 20-22 June 2018.

166. Perera, L.P.; Mo, B. Handling big-data in ship performance and navigation monitoring. In Maritime Industry IoT Developments, Supplement to the Naval Architect; The Royal Institution of Naval Architects: London, UK, 2017.

167. Perera, L.P.; Mo, B.; Nowak, M.P. Digitalization of seagoing vessels under high dimensional data driven models. In Proceedings of the ASME OMAE 2017, 36th International Conference on Ocean, Offshore and Arctic Engineering, Trondheim, Norway, 25-30 June 2017.

168. Perera, L.P.; Mo, B.; Nowak, M.P. Visualization of relative wind profiles in relation to actual weather conditions of ship routes. In Proceedings of the ASME OMAE 2017, 36th International Conference on Ocean, Offshore and Arctic Engineering, Trondheim, Norway, 25-30 June 2017.

169. Liu, S.; Loh, M.; Leow, W.; Chen, H.; Shang, B.; Papanikolaou, A. Rational processing of monitored ship voyage data for improved operation. Appl. Ocean Eng. 2020, 104, 102363. [CrossRef]

170. HOLISHIP. Integration for Better Design. Available online: http:/ /www.holiship.eu/holiship-integration-better-design (accessed on 22 January 2021).

171. Nielsen, B.J.; Sandvik, E.; Pedersen, E.; Asbjørnslett, E.B. KImpact of simulation model fidelity and simulation method on ship operational performance evaluation in sea passage scenarios. Ocean Eng. 2019, 188, 106268. [CrossRef]

172. Cunningham, J.D.; Simpson, T.W.; Tucker, C.S. An investigation of surrogate models for efficient performance-based decoding of 3D point clouds. J. Mech. Des. 2019, 141, 121401. [CrossRef]

173. DNV-GL. Digital Twin Report for Danish Maritime Authority. Digital Twins for Blue Denmark; Report No. 2018-0006; 2018. Available online: https:/ / www.dma.dk/Documents/Publikationer/Digital\%20Twin\%20report\%20for\%20DMA.PDF (accessed on 4 May 2021).

174. MONALISA 2.0 E-Navigation Testbed. Available online: www.iala-aism.org/technical/e-nav-testbeds/monalisa-2-0 (accessed on 7 December 2020).

175. Fujiwara, T.; Ueno, T.; Ikeda, Y. Cruising performance of a large passenger ship in heavy sea. In Proceedings of the 6th International Offshore and Polar Engineering Conference, San Francisco, CA, USA, 28 May-2 June 2006.

176. Marine Traffic. Available online: www.marinetraffic.com (accessed on 23 November 2020). 
177. SHOPERA. Energy Efficient Safe SHip OPERAtion Project. Available online: https://cordis.europa.eu/project/id/605221/it (accessed on 18 January 2021).

178. Miglietta, M.M. Mediterranean tropical-like cyclones (Medicanes). Atmosphere 2019, 10, 206. [CrossRef]

179. Cavicchia, L.; von Storch, H.; Gualdi, S. Mediterranean Tropical-Like Cyclones in present and future climate. J. Clim. 2014, 27, 7493-7501. [CrossRef] 